\title{
Critical Parameters for Coarse Coal Underground Slurry Haulage Systems
}

David P. Maynard

February 15, 1981

Prepared for

U.S. Department of Energy

Through an agreement with

National Aeronautics and Space Administration

by

Jet Propulsion Laboratory

California Institute of Technology

Pasadena, California 


\section{DISCLAIMER}

This report was prepared as an account of work sponsored by an agency of the United States Government. Neither the United States Government nor any agency Thereof, nor any of their employees, makes any warranty, express or implied, or assumes any legal liability or responsibility for the accuracy, completeness, or usefulness of any information, apparatus, product, or process disclosed, or represents that its use would not infringe privately owned rights. Reference herein to any specific commercial product, process, or service by trade name, trademark, manufacturer, or otherwise does not necessarily constitute or imply its endorsement, recommendation, or favoring by the United States Government or any agency thereof. The views and opinions of authors expressed herein do not necessarily state or reflect those of the United States Government or any agency thereof. 


\section{DISCLAIMER}

Portions of this document may be illegible in electronic image products. Images are produced from the best available original document. 


\section{Critical Parameters for Coarse Coal Underground Slurry Haulage Systems}

David P. Maynard

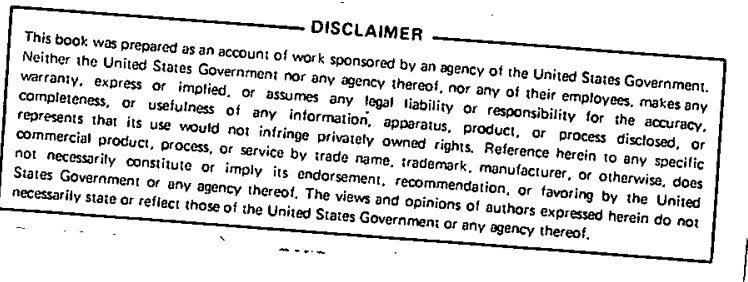

February 15,1981

Prepared for

U.S. Department of Energy

Through an agreement with

National Aeronautics and Space Administration

by

Jet Propulsion Laboratory

California Institute of Technology

Pasadena, California 
Prepared by the Jet Propulsion Laboratory, California Institute of Technology, for the U.S. Department of Energy through an agreement with the National Aeronautics and Space Administration:

This report was prepared as an account of work sponsored by the United States Government. Neither the United States nor the United States Department of Energy, nor any of their employees, nor any of their contractors, subcontractors, or their employees, makes any warranty, express or implied, or assumes any legal liability or responsibility for the accuracy, completeness or usefulness of any information, apparatus, product or process disclosed, or represents that its use would not infringe privately owned rights. 
This report describes the basic parameters which directly influence the behavior of a coal slurry pipeline transportation system and determine the limitations of the system performance. The purpose of this technology assessment is to provide an identification and understanding of the critical factors which must be given consideration in the design and evaluation of such a slurry haulage system intended for use in an underground coal mine. The slurry haulage system will be utilized to satisfy the transportation requirements of conveying, in a pipeline, the coal mined by a continuous mining machine to a storage location near the mine entrance or to a coal preparation plant located on the surface. 
FOREWORD

The information presented in this report was obtained as a result of a literature survey and interviews conducted in order to obtain an understanding of the existing knowledge pertaining to coal slurry transport systems. While a large quantity of information has been published reflecting previous investigations on the subject of slurries conveying small particle sizes, much less work has been done relative to slurries transporting large particle sizes. Consequently, the data presented herein must utilize, to a large extent, the available information relating to fine particle slurries. It is believed that the consolidation of the available information in one document will be of assistance in obtaining a preliminary understanding of the basic parameters that influence the behavior of an in-mine coal slurry haulage system. 
The work presented here represents interim results from the Advanced Coal Extraction Systems Definition Project, a study being performed at the Jet Propulsion Laboratory, Pasadena, California, for the Fossil Energy. Program, United States Department of Energy, via an interagency agreement with the National Aeronautics and Space Administration.

The author would like to express appreciation for comments and contributions made by several individuals. The continuing support of Mr. William Schmidt, Director of the Division of Fossil Fuel Extraction, U. S. Department of Energy is gratefully acknowledged. Mr. Anthony J. Miscoe of the Pittsburgh Mining Technology Center, U. S. Department of Energy and Messrs. Milton L. Lavin, Paul G. Gordon, William B. Mabe, Martin Goldsmith, and Nicholas R. Moore of JPL each performed a very constructive review of the document and provided useful comments. Finally, I would like to thank Ms. Patricia A. South for her expert preparation of this manuscript. 


\section{THIS PAGE}

WAS INTENTIONALLY

LEFT BLANK 
CONTENTS

I. INTRODUCTION . . . . . . . . . . . . . . . . . 1-1

A. BACKGROUND . . . . . . . . . . . . . . . . . 1-1

B. SYSTEM CONCEPT . . . . . . . . . . . . . . . . 1-2

II. SYSTEM DESIGN VARIABLES . . . . . . . . . . . . . . . 2-1

A. VELOCITY . . . . . . . . . . ......... 2-1

B. CAPACITY ...................... . 2-7

C. PRESSURE ...................... . . 2-10

D. SUMMARY. . ..................... 2-16

III. SUSPENSION PROPERTIES. . . . . . . . . . . . . . . . 3-1

A. PARTICLE SIZE .................... 3-3

B. SOLID CONCENTRATION ................. . . 3-5

c. DENSITY . . . . . . . . . . . . . . . . 3-7

D. VISCOSITY . . . . . . . . . . . . . 3-7

E. SUMMARY ....................... 3-8

IV. EQUIPMENT AND OPERATION ........................ . . . . .

A. PUMPS ....................... . . 4-1

B. PIPE AND VALVES . . . . . . . . . . . . . . . 4-6

C. INTERNATIONAL EXPERIENCE ................. 4-10

D. SUMMARY ........................ 4-10

V. SYSTEM PERFORMANCE . . . . . . . . . . . . . . . . . . 5-1

VI . REFERENCES . . . . . . . . . . . . . . . . . . 6-1

\section{Figures}

1-1. Abbreviated System Schematic . . . . . . . . . . 1-2

2-1. Typical Shear Stress - Strain Rate Relationships . . . . . 2-2 
2-2. Typical Shear Stress - Velocity Relationship . . . . . . 2-4

2-3. Variation of Parameter $\mathrm{F}_{\mathrm{L}}$. . . . . . . . . . . 2-6

2-4. Pressure Loss Versus Velocity. . . . . . . . . . . 2-8

2-5. Coal Delivery Rate as a Function of Slurry Capacity . . . 2-9

2-6. Coal Delivery Rate as a Function of Slurry Velocity,
$\mathrm{C}_{\mathrm{V}}=40 \%$. . . . . . . . . . . . . . . 2-11

2-7. Representative Centrifugal Pump Performance Characteristics . 2-12

2-8. Representative Positive Displacement Pump Performance
Characteristics . . . . . . . . . . . . . . . . . . . . . . . . . .

2-9. Pipe Friction Factors . . . . . . . . . . . . 2-15

3-1. Slurry Flow Regime Particle Distribution . . . . . . . 3-2

3-2. Slurry Flow Classification . . . . . . . . . . . 3-4

3-3. Solids Concentration by Weight and Volume. . . . . . . 3-6

3-4. Relative Viscosity as a Function of Solids Concentration . 3-9

4-1. Variable Speed Centrifugal Pump Performance . . . . . . . 4-4

4-2. High Pressure Injection Scheme . . . . . . . . . . . 4-7

4-3. Lockhopper System Diagram . . . . . . . . . . . . 4-8

5-1. System Performance Envelope, $c_{v}=30 \%$. . . . . . . 5-2

5-2. System Performance Envelope, $C_{v}=40 \%$. . . . . . . . 5-3

5-3. System Performance Envelope, $c_{v}=50 \%$. . . . . . . . . 5-4

Tables

4-1. Slurry Pump Performance Limitations . . . . . . . . . 4-3 


\section{SECTION I}

\section{INTRODUCTION}

The Jet Propulsion Laboratory is under contract to the United States Department of Energy to define, develop, and demonstrate advanced systems for underground coal mining. It is required that the systems for use beyond the year 2000 produce coal substantially below the production costs of existing systems. For the purpose of satisfying this task, the performance characteristics of an advanced mining system have been categorized into five primary areas: conservation, environmental protection, miner health, miner safety, and production cost. The evaluation of any advanced system must include an appraisal of the improvement anticipated in these five areas in order to determine its benefit to the mining industry as it now exists.

\section{A. BACKGROUND}

Current projections of areas deserving emphasis for future mining systems technological innovations include haulage. Two of the primary reasons why haulage is considered to be one of the most critical areas of coal mining activity to be improved are that (1) it is important to the continuity of the mining activity and (2) it has a significant effect upon the safety of the mine workers. Continuous mining machines cannot be operated without interruption as a result of the inability of other operations, including haulage, to handle its capacity of coal output. Accidents involving contemporary haulage systems are second only to rockfalls in regard to their potential hazard to the miner and they may occur at any location throughout the mine. The objective of this technology assessment task has been to provide an understanding of the basic parameters which directly influence the behavior of a slurry haulage system and determine its performance limitiations.

A coarse particle slurry haulage system has been considered by many investigators to be a viable alternative to the conventional method of in-mine coal transportation via shuttle cars and belt conveyors. Such a slurry haulage system would consist of hydraulic subsystems for conveying lun-of-mine coal via pipeline from the continuous mining machines located at the face of the underground coal seam to a surface loading destination or preparation plant. Alleged advantages of this means of conveyance include improved health and safety for the miners and increased mine productivity. These benefits are anticipated because the slurry haulage. system will

(Ref. 1):

(1). Reduce the number of transporation transfer points and lessen the quantity of moving equipment located underground, leading to fewer operational delays and safety hazards.

(2) Entrain the coal dust and methane gas within the water, thus reducing the possibility of dust explosions and eliminating the generation of airborne dust at locations away from the seam face. 
(3) Minimize the occurrence of spillage in transit which creates hazardous situations for miners and results in lost time for clean-up along the tracks and belts.

\section{B. SYSTEM CONCEPT}

References made in this report to the slurry haulage system are, in actuality, describing a subsystem. Figure 1-1 illustrates this concept, and the boundaries of the sluriy haulage system which was considered are shown by dashed lines. It should be noted that neither the winning nor breaking functions, which are necessary operations that must be performed at the front end of the transport system, are within the system boundaries. The usual dewatering, cleaning, and sizing operations, which are typically performed at the coal preparation facility located on the surface, also lie outside the scope of this study. Consequently, the intent of this report is to provide useful information for (1) characterizing the slurry flow, (2) describing the influences and operational limitations which result from varying significant parameters, and (3) furnishing equipment design and utilization considerations for the conveyance of mined and broken coal via a water slurry from the seam face in an underground mine to a surface destination immediately outside of the mine entrance.

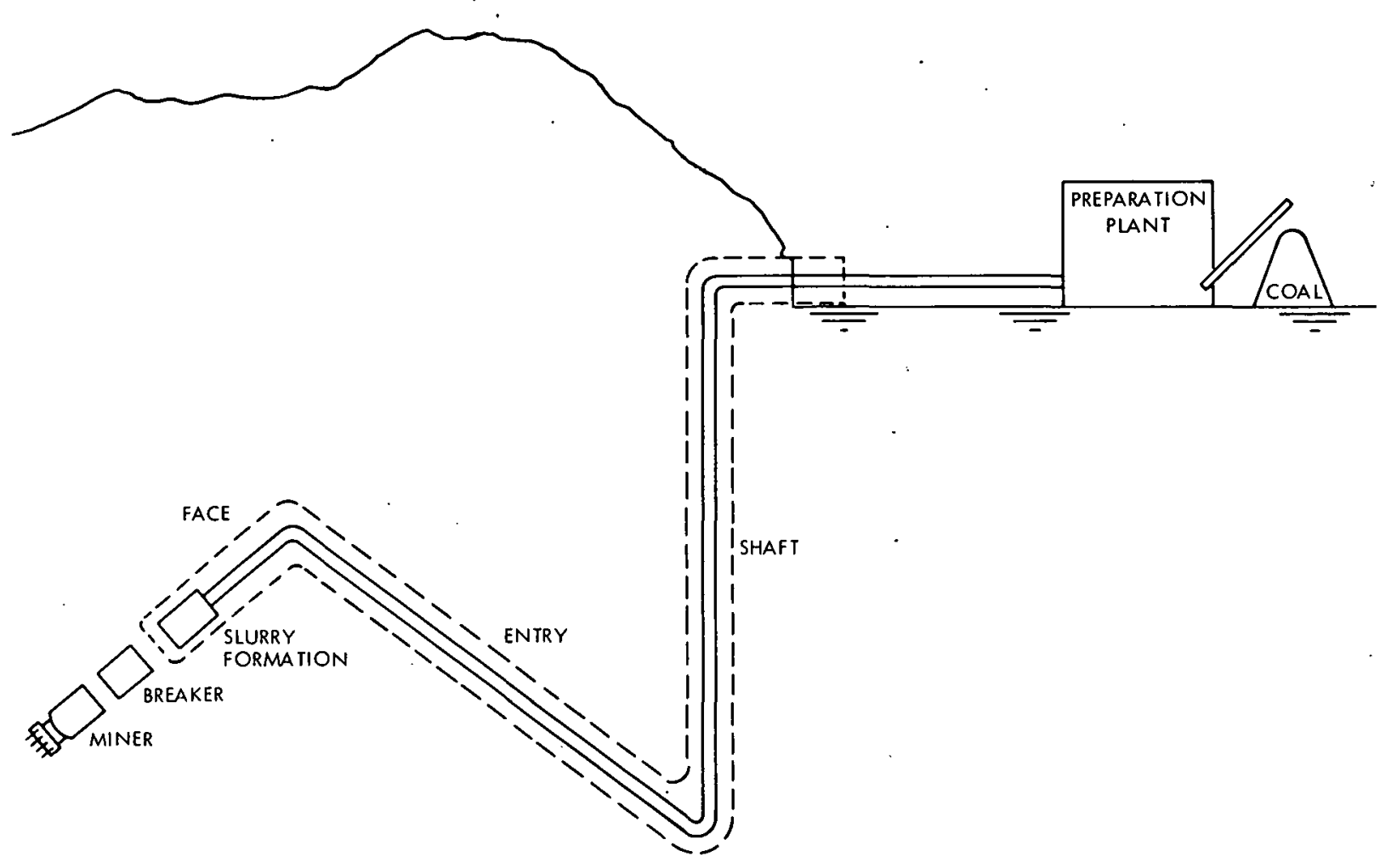

Figure 1-1. Abbreviated System Schematic 
SECTION II

SYSTEM DESIGN VARIABLES

Before commencing any discussion of slurry transport and the critical parameters which govern the flow characteristics, it is first necessary to present some fundamental concepts. The first of these is identifying the type of fluid which most accurately describes the behavior of the slurry. One of the most general ways of defining flow (Refs. 2 and 3 ) is whether or not it can be considered a Newtonian fluid. A Newtonian fluid is one, such as water, whose viscosity $(\mu)$ is constant and is independent of shear rate $(\dot{\gamma})$ and where the shear rate $(\dot{\gamma})$ is linearly proportional to shear stress $(\tau)$. This relationship is expressed by $\tau=\mu \dot{\gamma}$.

Fluids which do not obey this linear relationship are known as non-Newtonian fluids and are usually grouped in one of the three general classifications of (1) time independent, (2) time dependent, or (3) viscoelastic fluids. The majority of the non-Newtonian fluids that are normally encountered fall into the category of time independent fluids, and they are the simplest to characterize mathematically. In some cases, flow of time dependent fluids may be approximated as time independent fluids for simple situations such as steady flow in pipe.

Time independent non-Newtonian fluids are those in which the shear rate is a unique but non-linear function of the shear stress, and they are commonly represented (see Refs. 2 and 3 ) by the three distinct types of (1) Binghamplastics, (2) pseudoplastics, and (3) dilatants. Most.slurries utilized in pipeline transport exhibit Bingham-plastic characteristics, as do emulsions such as paint, and suspensions of finely divided solids in a liquid such as drilling muds. All of these fluids exhibit no flow until a definite yield point is reached. This yield stress $\left(\tau_{y}\right)$ is necessary in order to overcome the static friction of the fluid particles after which the shear rate is linearly proportional to the shear stress. The characterisitics of these fluids are defined by two constants: the yield stress, $\tau_{y}$, which must be exceeded for flow to begin, and the plastic viscosity, $\mu_{\mathrm{p}}$. This relationship is expressed by the equation $\tau=\tau_{\mathrm{y}}+\mu_{\mathrm{p}} \dot{\gamma}$. The typical shear stress-strain rate relationship for Newtonian and Bingham-plastic fluids is shown in Figure 2-1.

\section{A. VELOCITY}

It is a well known and significant fact that the friction loss experienced for flow in a pipe is dependent upon the velocity of flow. Hagen and Poiseuille (see Ref. 3) conducted experiments showing that under certain conditions friction loss varied directly with velocity. However, Darcy (see Ref. 3) later concluded that friction loss was approximately proportional to the square of the mean velocity. Subsequently, the experiments conducted by Reynolds (see Ref. 3) proved both to be correct by demonstrating that the laws of flow with both small and large velocities showed great differences both quantitatively and qualitatively. 


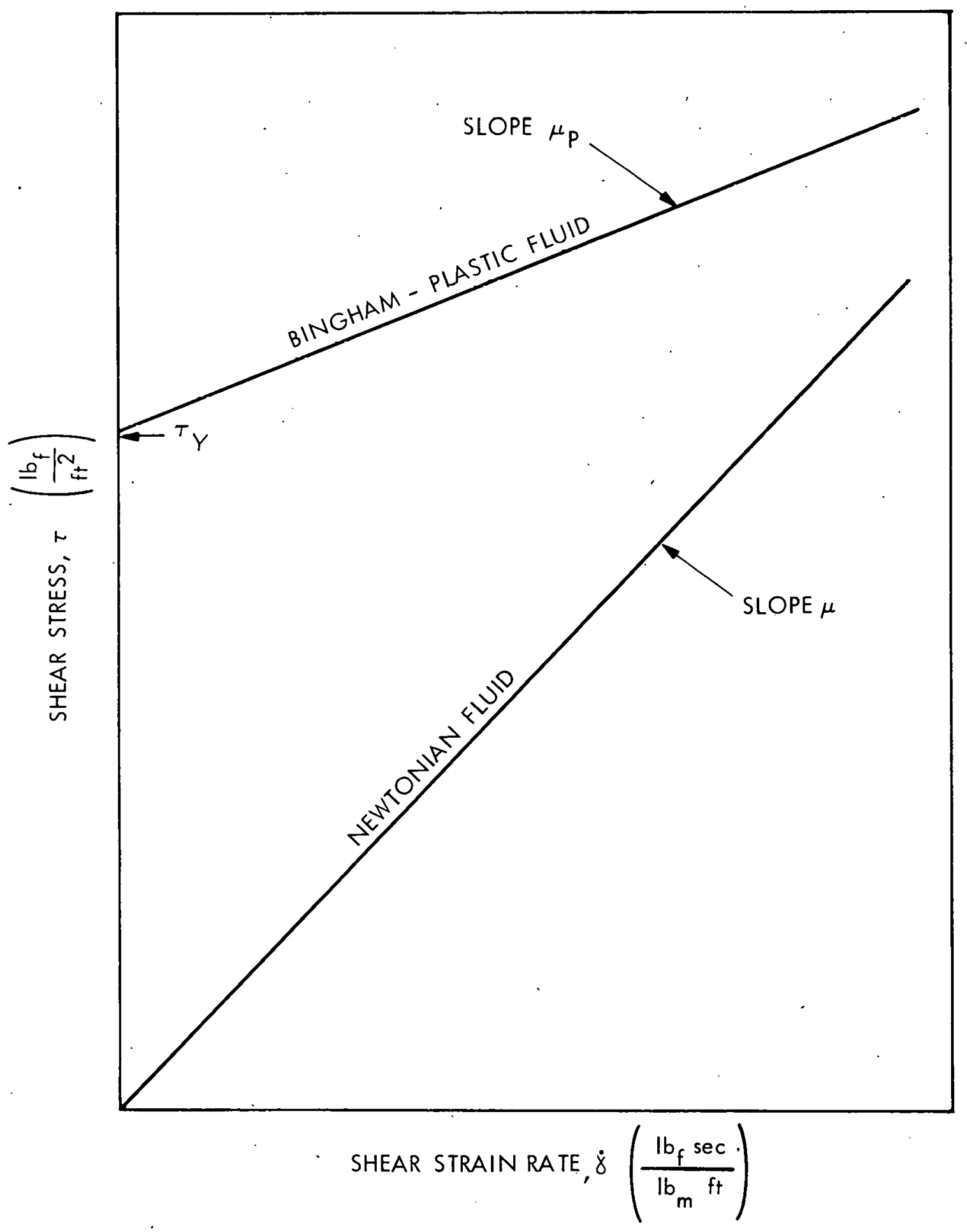

Figure 2-1. Typical Shear Stress - Strain Rate Relationships 
In essence, when the velocity of flow for a given pipeline is below a certain critical value, the flow is found to be laminar, or of a we11-ordered pattern whereby fluid layers are assumed to slide over one another. However, when the velocity of the flow is above the critical velocity, the flow is found to be turbulent or of a nature where the particles of the fluid move in an irregular fashion and it is impossible to predict the motion of an individual particle. It was found that the change from laminar to turbulent flow results in a large increase in the flow resistance and also in a modification of the relationship between friction loss and the mean velocity of the flow.

Reynolds used the principle of dimensional analysis in order to understand this phenomenon of transition from laminar to turbulent flow. He concluded that the transition occurred at a fixed value of a dimensionless number which is the ratio of the inertia forces to the viscous forces acting upon an element of the fluid. The Reynolds number which illustrates this relationship can be expressed at $\mathrm{R}_{e}=\frac{\rho^{\mathrm{VD}}}{\mu}$.

The relationship between the mean flow velocity $(V)$ and the pipe wall shear stress $\left(\tau_{w}\right)$ is shown in Figure 2-2. Figure 2-2 illustrates that at the lower velocities associated with laminar flow, the slope of the curve is unity. However, as the velocity is increased, the slope of the curve is characterized by a steep linear response in the turbulent flow regime. The velocity at which the flow regime makes the transition from laminar to turbulent is known as the transition or critical velocity. The Reynolds number associated with the transition velocity is usually from 2300 to 4000 depending upon the presence of small disturbances sufficient to initiate the transition. This value is referred to as the critical Reynolds number.

One of the primary reasons for laying this fundamental and abbreviated groundwork in fluid mechanics has been to present a brief understanding of turbulent flow. When dealing with slurry transport, it is generally necessary that the hydraulic conditions ensure turbulent flow in order to prevent the settling of solids in the pipe. However, when pumping slurries of coarse coal in black water or water in which there is a significant quantity of coal fines homogenously suspended, the coal fines increase the apparent viscosity of the mixture and subsequently improve the carrying capacity of the transport media. As a result, for a given volumetric concentration of coal, the deposition velocity is decreased towards the laminar flow regime resulting in lower power requirements. The deposition velocity of slurry flow in a pipe is that flow rate below which the particles start to form a sliding bed on the bottom of the pipe. This phenomenon can eventually cause the flow to become unstable and the pipe to clog. At the deposition velocity, the tendency of the solid particles of the slurry to settle under gravitational forces just exceeds the turbulence forces tending to maintain the particles in suspension. General practice has been to design the system so that the slurry velocity exceeds the deposition velocity by at least $30 \%$ in order to provide a conservative margin of safety.

The deposition velocity can clearly be experienced in a heterogeneous suspension which is operating in the turbulent flow range such as a coalwater slurry, and it is a function of the fall velocity of the individual particles as well as the degree of turbulence which exists in the system. Consequently, the deposition velocity can be expected to increase with an 


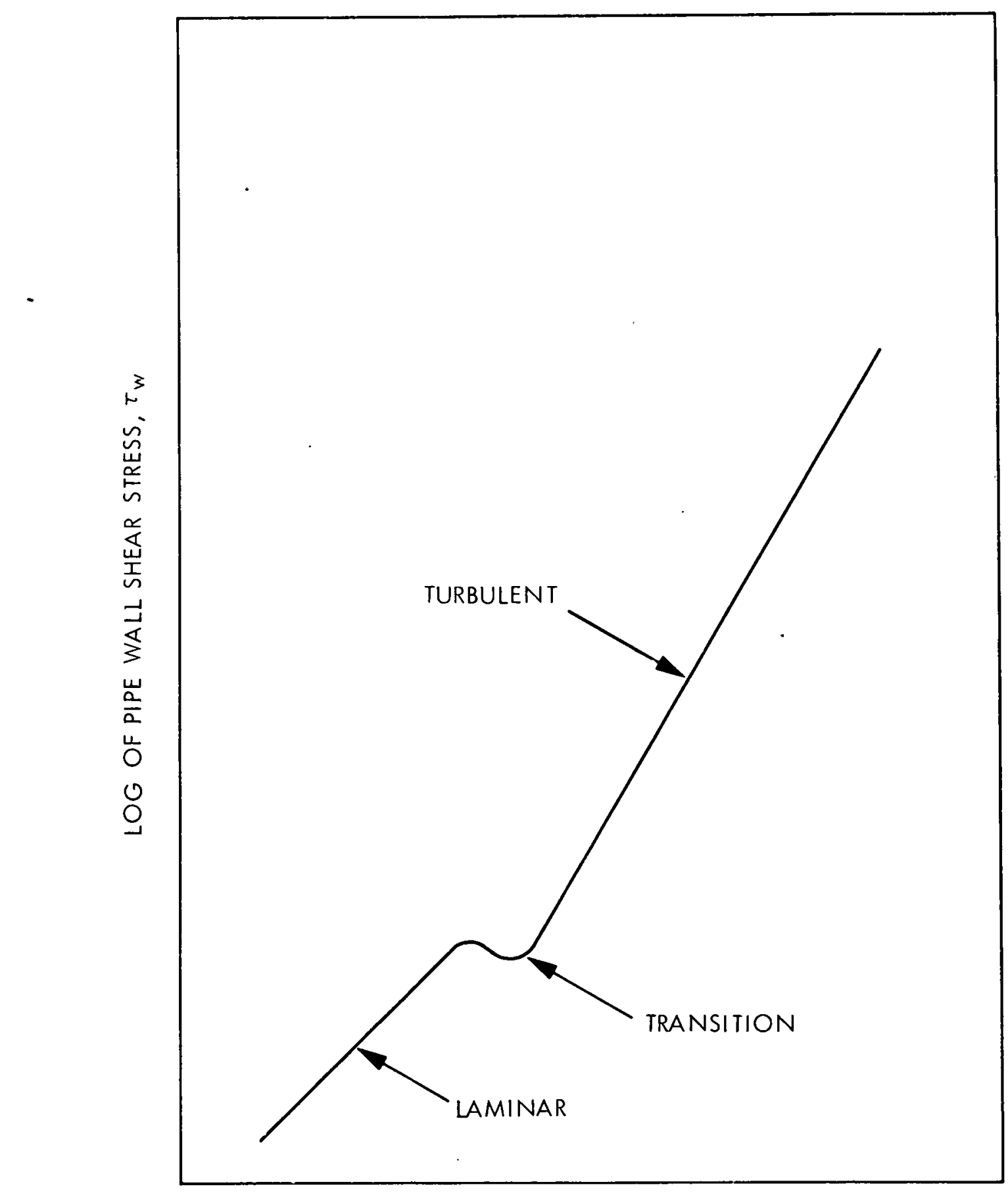

LOG OF MEAN FLOW VELOCITY, $V$

Figure 2-2. Typical Shear Stress - Velocity Relationship 
increase in the particle size, particle density, solids concentration, and pipe diameter.

Previous investigators have attempted to provide a means of calculating the deposition velocity. One of the best known correlations is that which was suggested by Durand (Ref. 4):

$$
v_{D}=F_{L} \sqrt{2 g D\left(\frac{S G_{s}-S G_{L}}{S G_{L}}\right)}
$$

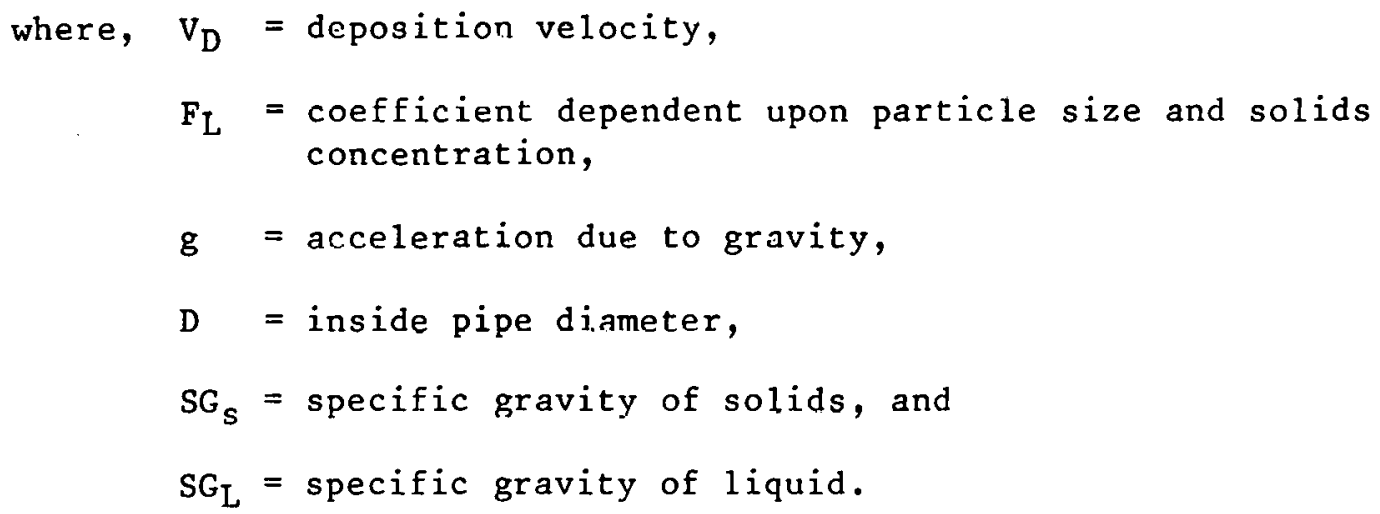

The value for $F_{L}$ must be determined from the properties of a given system. For particle sizes up to approximately $1 \mathrm{~mm}$ in diameter, $\mathrm{F}_{\mathrm{L}}$ is a function of particle size and the volumetric concentration of solids in the slurry. Figure 2-3 (Ref.5) illustrates the variation of $F_{L}$ as a function of particle diameter. As the particle size becomes larger, the value for $F_{L}$ becomes independent of system properties (see Ref. 3) and a rough approximation of the deposition velocity for coal-water slurries with a particle size larger than $2 \mathrm{~mm}$ is

$$
\mathrm{V}_{\mathrm{D}} \cong 7 \sqrt{\mathrm{D}}
$$

where the units of $D$ are given in feet and $V_{D}$ is calculated in feet per second. Durand's work (see Refs. 3 and 4, and Ref. 6) was limited to granular slurries of sand with a uniform particle size, having a volumetric concentration of solids no greater than $15 \%$. However, slurries consisting of uniform sized particles are not common in commercial practice and are certainly not the case for the coal- water slurries. The prediction of the critical deposition velocity becomes significantly more complicated for slurries composed of particles of mixed or graded sizes. The deposition velocity calculations for such slurries are usually estimated by assigning a mean particle size ( $d_{50}$ ) to the suspension, where the $d_{50}$ size is that particle size for which $50 \%$, by weight, of the solid particles are coarser and $50 \%$ are finer. However, there is no method to accurately calculate the deposition velocity of all slurry system combinations particularly those consisting of a high solids concentration of mixed sized particles. Consequently, the previous method can be utilized for approximating the situation to size the equipment; however, for a precise determination, empirical results should be obtained by experimentation. 


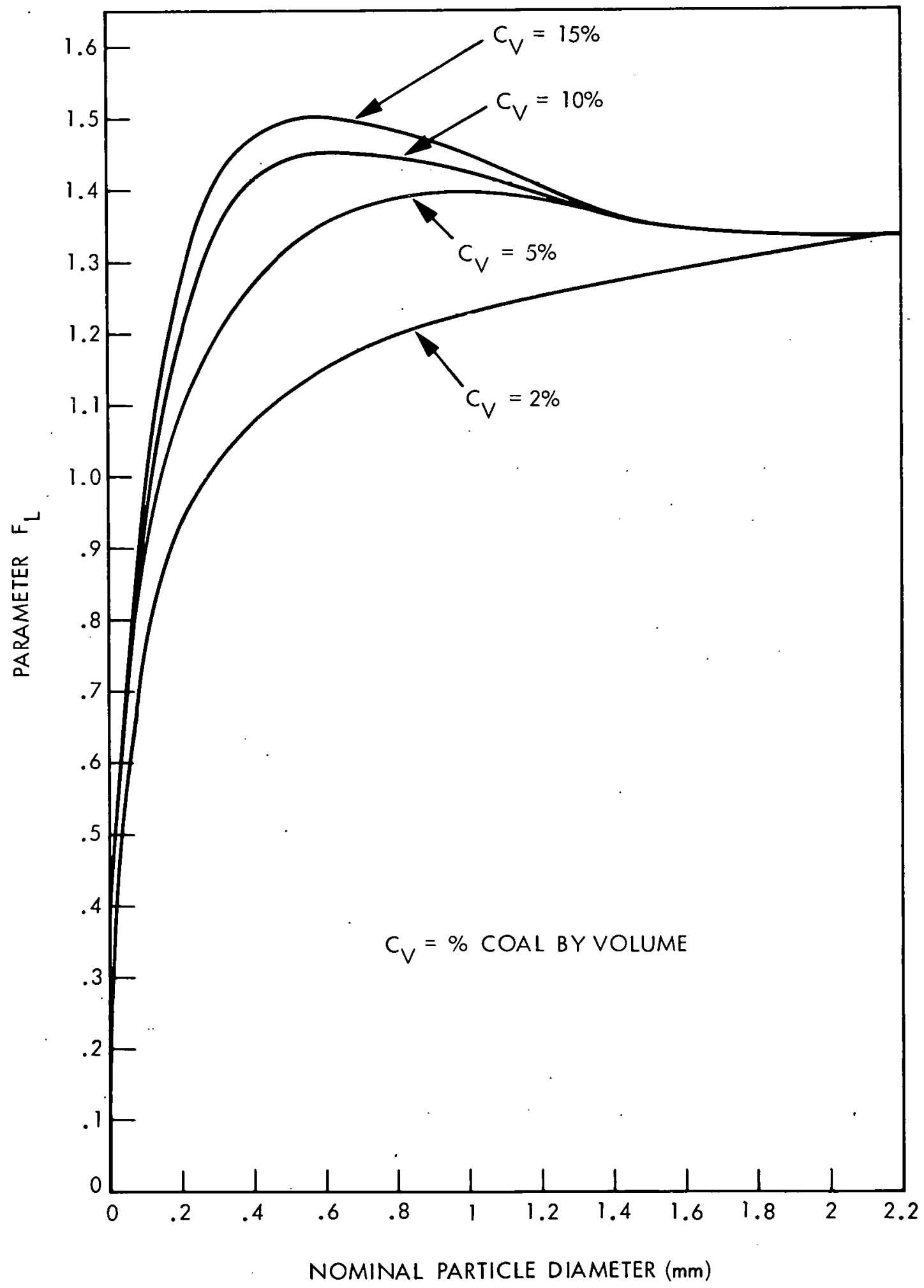

Figure 2-3. Variation of Parameter $F_{L}$ 
In conclusion, the importance of optimizing the transport velocity is obvious. If the velocity is too low, the solids will be allowed to settle out of the suspension, possibly creating blockages in the pipeline; on the other hand, unnecessary expense is incurred by providing a pipeline larger than the requirements warrant. Moreover, if the velocity is too high, then friction losses, power consumption, and wear on the pumps and pipeline will be excessive. For any slurry pipeline system with a given solids capacity and pipe size, the lowest pressure loss is experienced at the point where the flow makes the transition from the laminar to the turbulent regime, as shown in Figure 2-4. Even though this point of minimum pressure loss also happens to be the most economical operating point in terms of power usage per unit weight of solids transported, the operating velocity must be maintained above this value in order to prevent problems arising from deposition of the solid particles.

\section{B. CAPACITY}

The capacity of the system or the quantity of slurry to be transported is, of course, dependent upon the total quantity of solids which needs to be conveyed and the allowable loading of the liquid carrier. It is desirable to design the system to transport as great a percentage of coal as possible, since the purpose of the liquid (water) in the slurry is to serve only as the carrier for the coal, and provides no economic benefit, unless it is possible in some situations to use the mine drainage water for this purpose. In this case, it may be possible that the slurry system could serve a two-fold purpose, that of mine dewatering as well as coal transport. It is desirable that the capacity of the system be such that it is capable of removing the coal from the mine at a rate nearly equivalent to the rate at which it is mined from the seam face, in order to minimize bottlenecks and delays or the necessity for storage.

The issue of the concentration of solids, which is practical for a coal-water slurry, will be dealt with in Section III B. The determination of the desired throughput of the system is a function of the production capability of the mining equipment itself. This will vary from mine to mine and even within a given mine depending upon whether a continuous or longwall operation is being used.

However, it is possible to provide some illustrations which would assist in the design of a continuous slurry haulage system. Since pumps are categorized by their capacity or flow rate in units of volume per unit of time, Figure 2-5 shows the corresponding slurry throughput in gallons per minute of slurry for various coal production rates in terms of tons per minute. This type of information is necessary in order to obtain some idea of the size of pump which is required for the system design. Individual manufacturers can be consulted in order to obtain the physical dimensions of pumps and drivers so that equipment is acquired which satisfies the size constraints of a specific application. Within a 5-ft high entry, it should be possible to utilize equipment which is capable of delivering approximately 6000 to 8000 gal/min of slurry. 


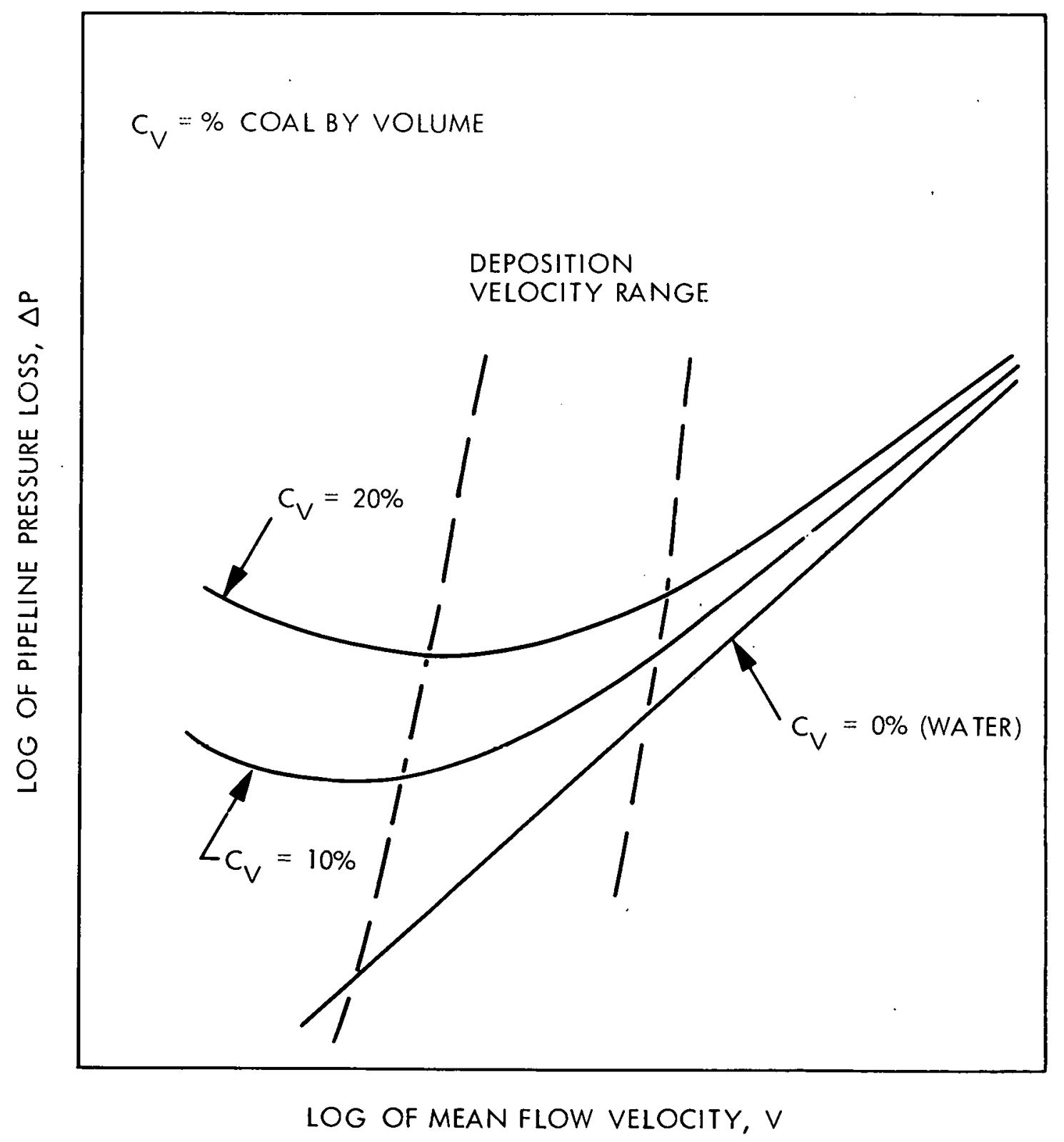

Figure 2-4. Pressure Loss Versus Velocity 


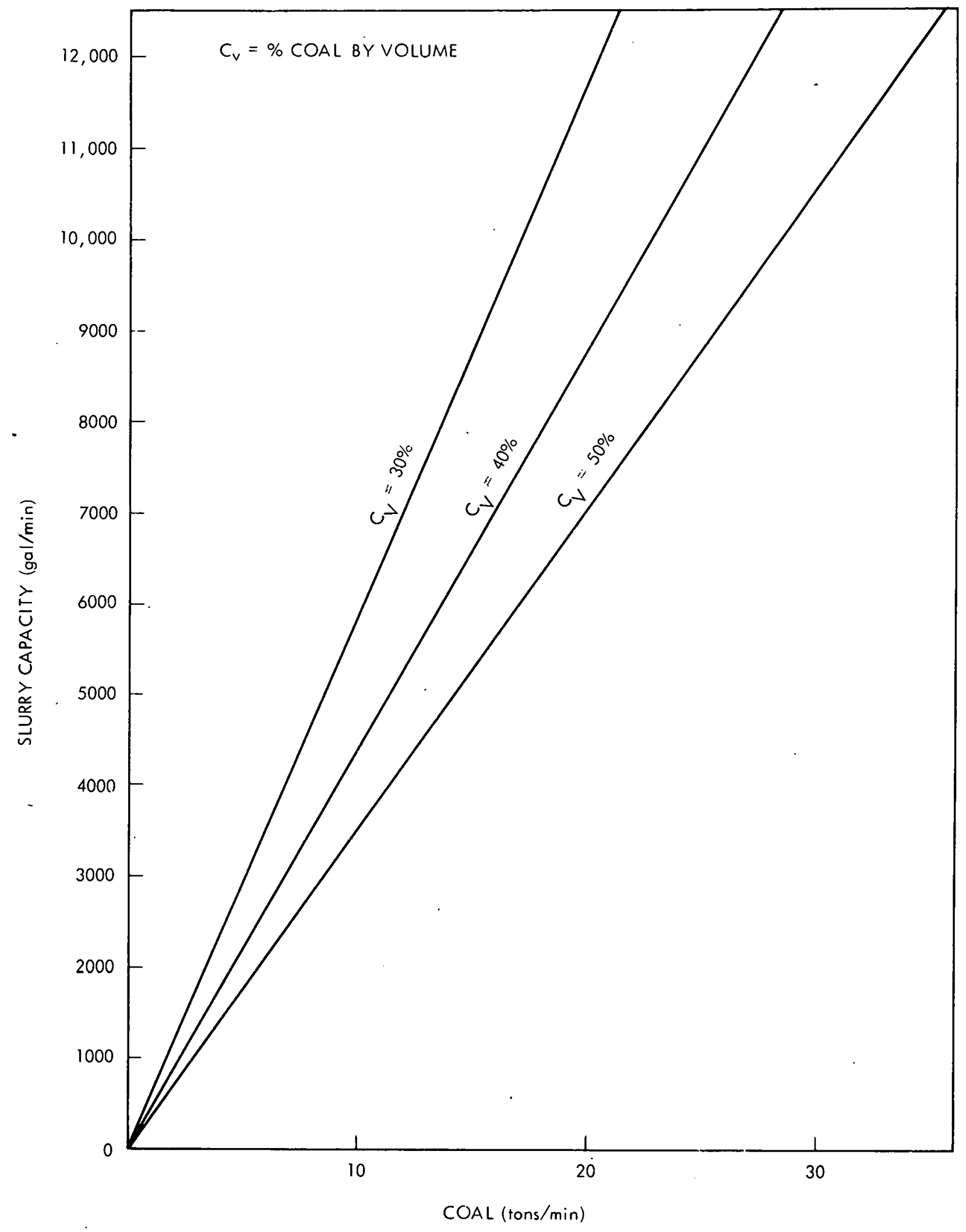

Figure 2-5. Coal Delivery Rate as a Function of Slurry Capacity 
Figure 2-6 provides correlation relative to coal delivery rates and the various pipe sizes which are necessary in order to obtain a predetermined slurry velocity. This type of information is required to size the pumps and pipes that are needed for a particular slurry haulage application. When the system is designed to recycle the water after the coal has been removed, then provision must also be made for the necessary return water piping.

\section{PRESSURE}

The required pressure that must be supplied by the pump(s) in the design of a slurry haulage system is the other critical flow parameter which must be determined at the beginning of such a venture. The typical manner of presenting the performance of pumping equipment is by means of a head-capacity curve. This curve presents the discharge pressure which is generated by the pump at various flow rates. A typical representation of this data for a centrifugal pump handling water is shown in Figure 2-7. Figure 2-8 depicts the performance curve for a positive displacement pump handling water. It is usually the case that as the centrifugal pump capacity increases, the pressure generated decreases. However, positive displacement pumps can generate a wide range of discharge pressure over a relatively constant capacity. Frequently, mechanical efficiency and required power information are presented on the performance curve. The pump curve usually assumes water as the working fluid, and the performance must therefore be corrected to compensate for the slurry effects. McElvain (Ref. 7) has presented a means of predicting the performance effects upon pumps handling slurries containing small particles, but the means to derate the performance of pumps handing high volumetric concentrations of large particles is not yet mastered.

The resistance to flow as a slurry is moved through a pipe results in a loss of head or pressure and is called friction (measured in feet). This resistance to $\mathrm{flow}$ is due to viscous shear stresses and turbulence that occurs along the pipe walls due to roughness. The pump discharge pressure must be adequate to overcome these friction losses and to satisfy the lift requirements which exist as a result of the elevation differences between the coal seam face and the mine entrance or some other predetermined delivery point.

The friction losses present in the system are significantly different for the horizontal and the vertical portions of the pipeline (Ref. 8). As was previously shown in Figure 2-4, the friction loss in a horizontal pipe increases with velocity. When dealing with slurries containing low volumetric concentrations of solids (less than 20\%) and consisting of small size particles (under 150 microns) distributed uniformly in the 1 iquid, it can be assumed, as a general guideline, that the friction loss is the same as the water friction loss and can be predicted in a straightforward manner. The frictional resistance to flow, $h_{f}$, in feet of water is expressed as follows by the Darcy-Weisbach equation (see Ref. 8):

$$
h_{f}=f \frac{L}{D} \frac{v^{2}}{2 g}
$$




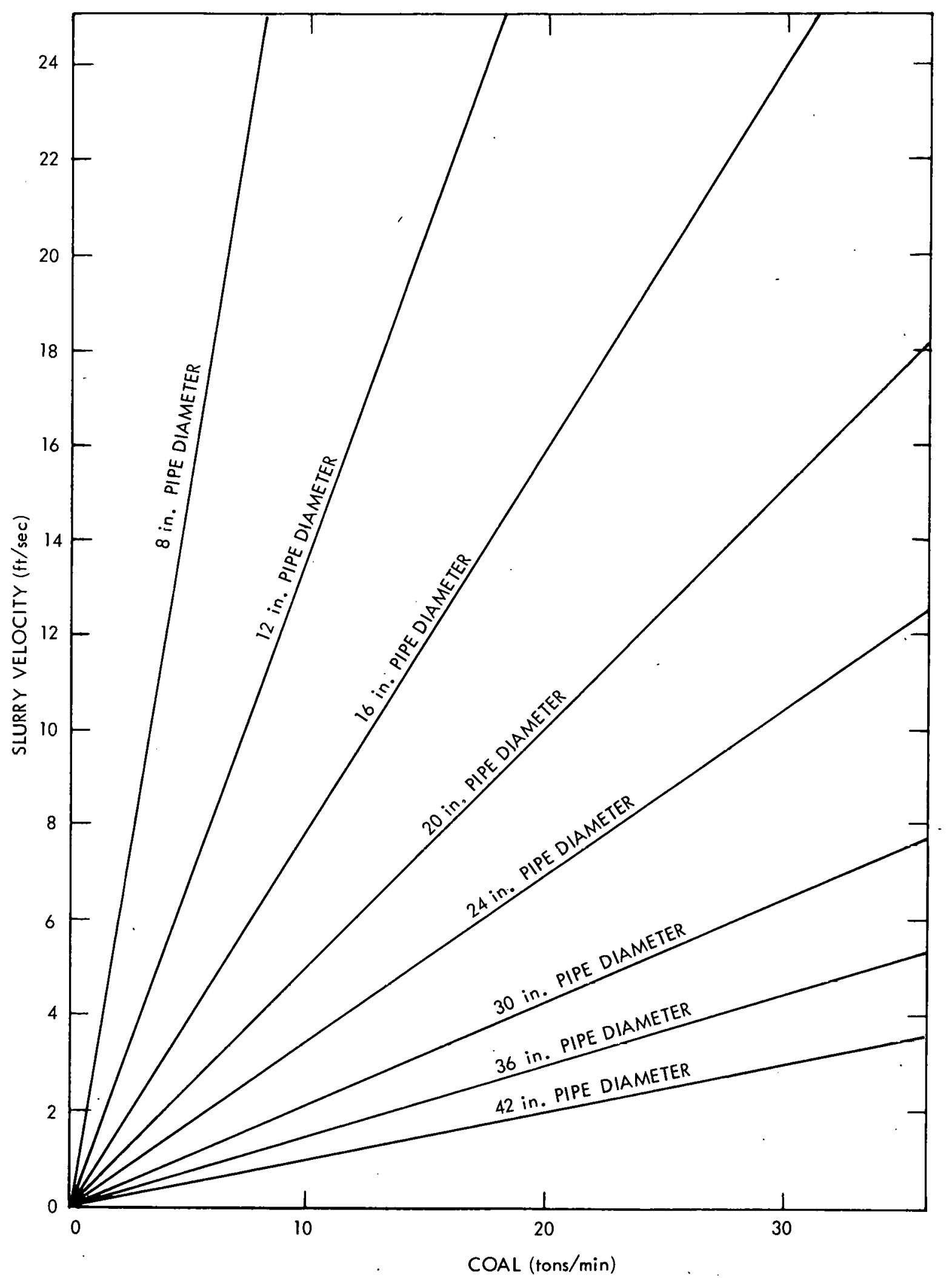

Figure 2-6. Coal Delivery Rate as a Function of Slurry Velocity, $C_{V}=40 \%$ 


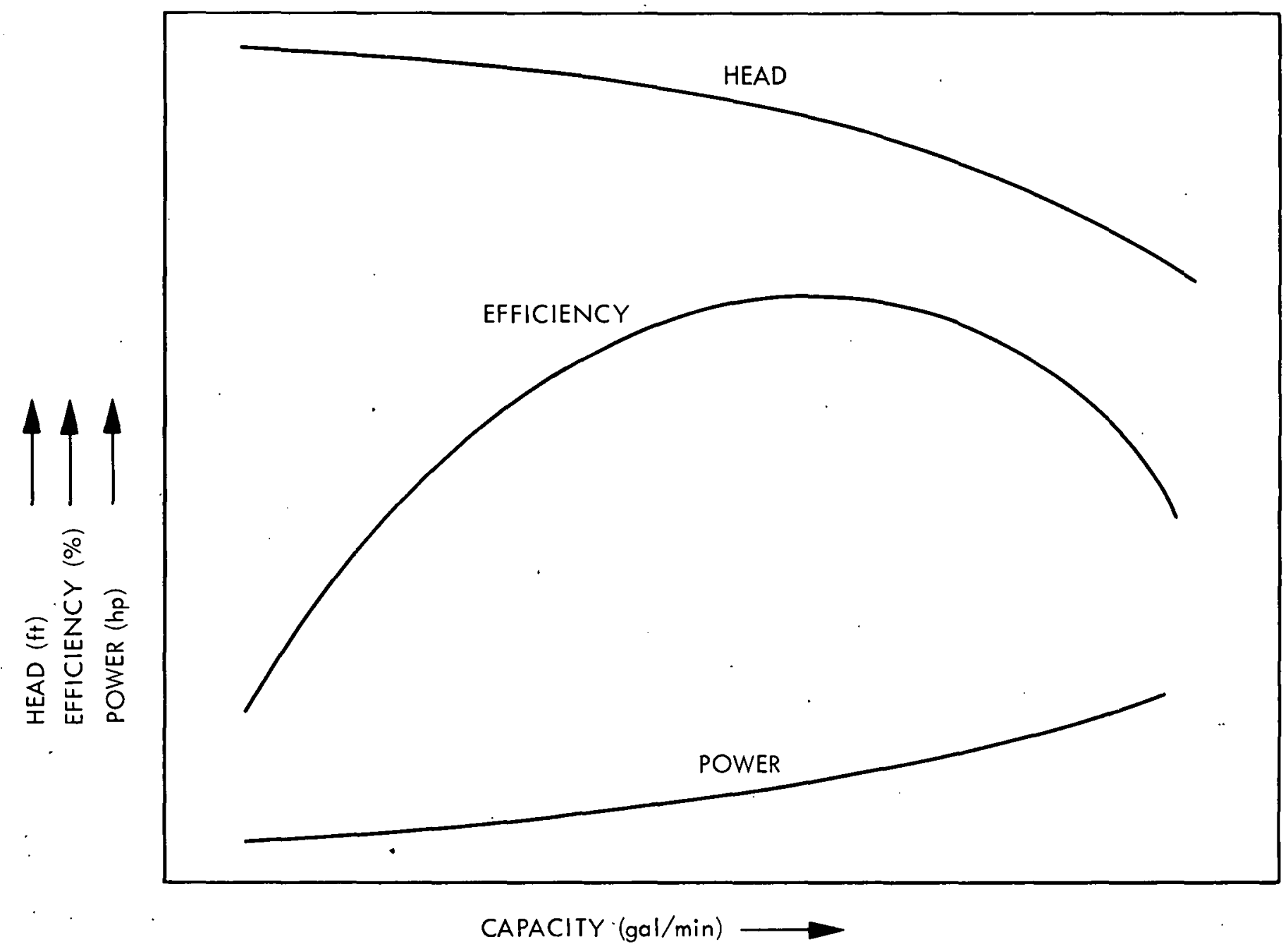

Figure 2-7. Representative Centrifugal Pump Performance Characteristics 


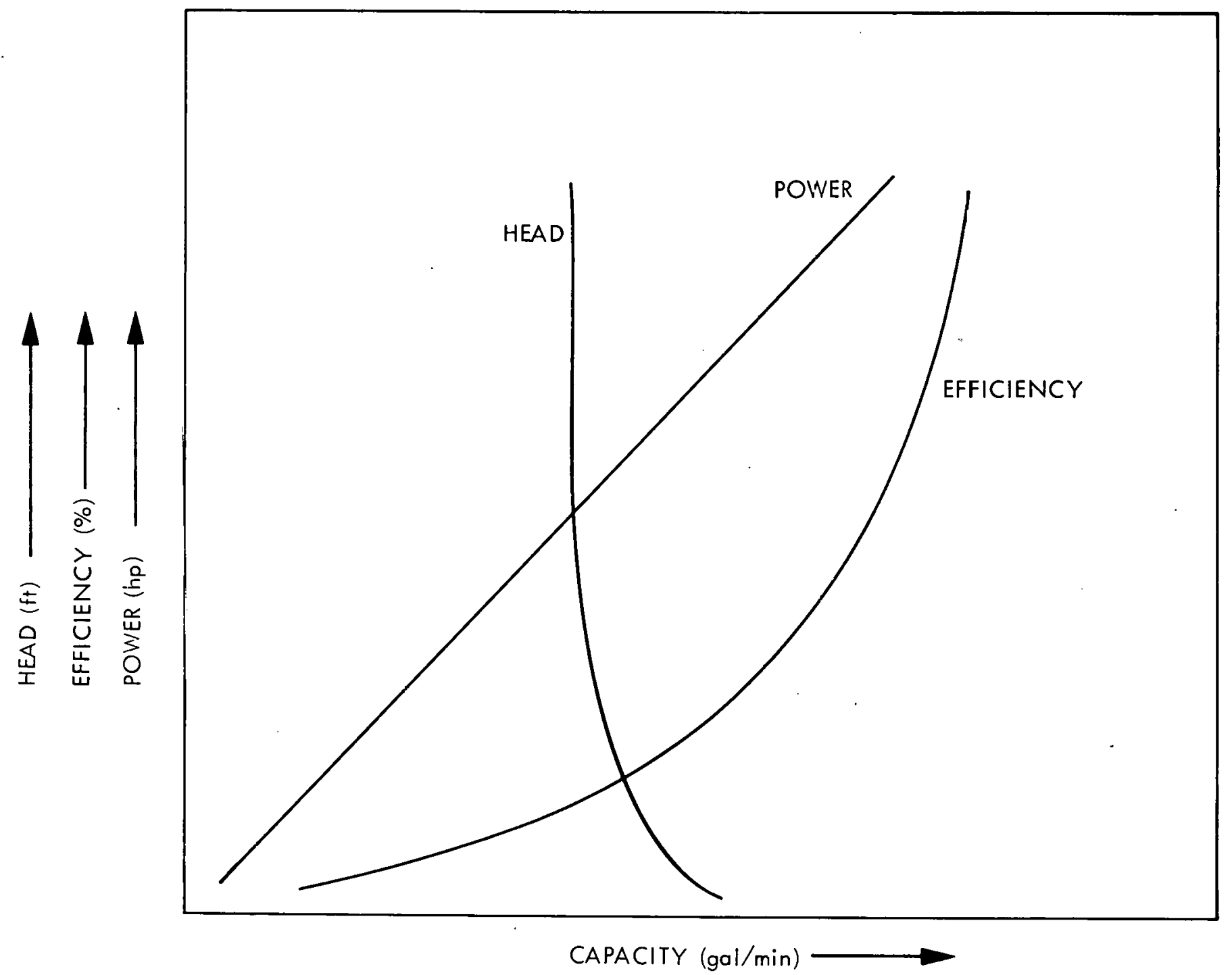

Figure 2-8. Representative Positive Displacement Pump Performance Characteristics 
where, $f=$ friction factor,

$\mathrm{L}=$ length of pipe,

$\mathrm{D}=$ internal diameter of pipe,

$\mathrm{V}=$ average velocity in pipe, and

$g$ = acceleration due to gravity.

Values of $f$ for the flow of water in pipes have been empirically determined and tabulated on curves (Ref. 9) such as shown in Figure 2-9. However, it is usually the case that for slurry haulage situations, one will be dealing with a relatively high concentration of solids, some of which will be quite large in size and nonuniformly distributed within the liquid carrier. In. such instances, the determination of the predicted friction loss, $h_{f}$, is not a simple matter due to the difficulty in accurately defining the friction factor, $f$, for the slurry mixture.

An approximation of $f$ is based upon Durand's work. Durand has provided an equation for calculating the friction factor $\left(f_{m}\right)$ of a slurry mixture consisting of uniform sized particles operating at a velocity greater than the deposition velocity. This equation is expressed as follows:

$$
\mathrm{f}_{\mathrm{m}}=\mathrm{f}_{1}\left\{1+\mathrm{K}\left[\left(\frac{\mathrm{gD}}{\mathrm{v}^{2}}\right)\left(\frac{\rho_{\mathrm{s}}-\rho_{1}}{\rho_{1}}\right) \frac{1}{\sqrt{\mathrm{C}_{\mathrm{D}}}}\right]^{1.5} \mathrm{C}\right\}
$$

where, $f_{m}=$ friction factor for mixture,

$$
\begin{aligned}
& \mathrm{f}_{1}=\text { friction factor for liquid, } \\
& \mathrm{C}=\text { volume fraction of solids, } \\
& \mathrm{K}=\text { Constant }=80-150, \\
& \mathrm{~g}=\text { acceleration due to gravity, } \\
& \mathrm{D}=\text { pipe diameter, } \\
& \mathrm{V}=\text { velocity of flow, } \\
& \rho_{\mathrm{S}}=\text { density of solids } \\
& \rho_{1}=\text { density of } 1 \text { iquids, and } \\
& \mathrm{C}_{\mathrm{D}}=\text { particle drag coefficient. }
\end{aligned}
$$

This equation can also be applied to slurries consisting of a mixed particle size range. This is done by using the appropriate drag coefficient, $C_{D}$, for each particle size fraction and calculating the friction factor for each size fraction as a discrete entity. The summation of the individual friction factor contributions for each particle size fraction will then give an estimation of the total friction factor, $f_{m}$. 


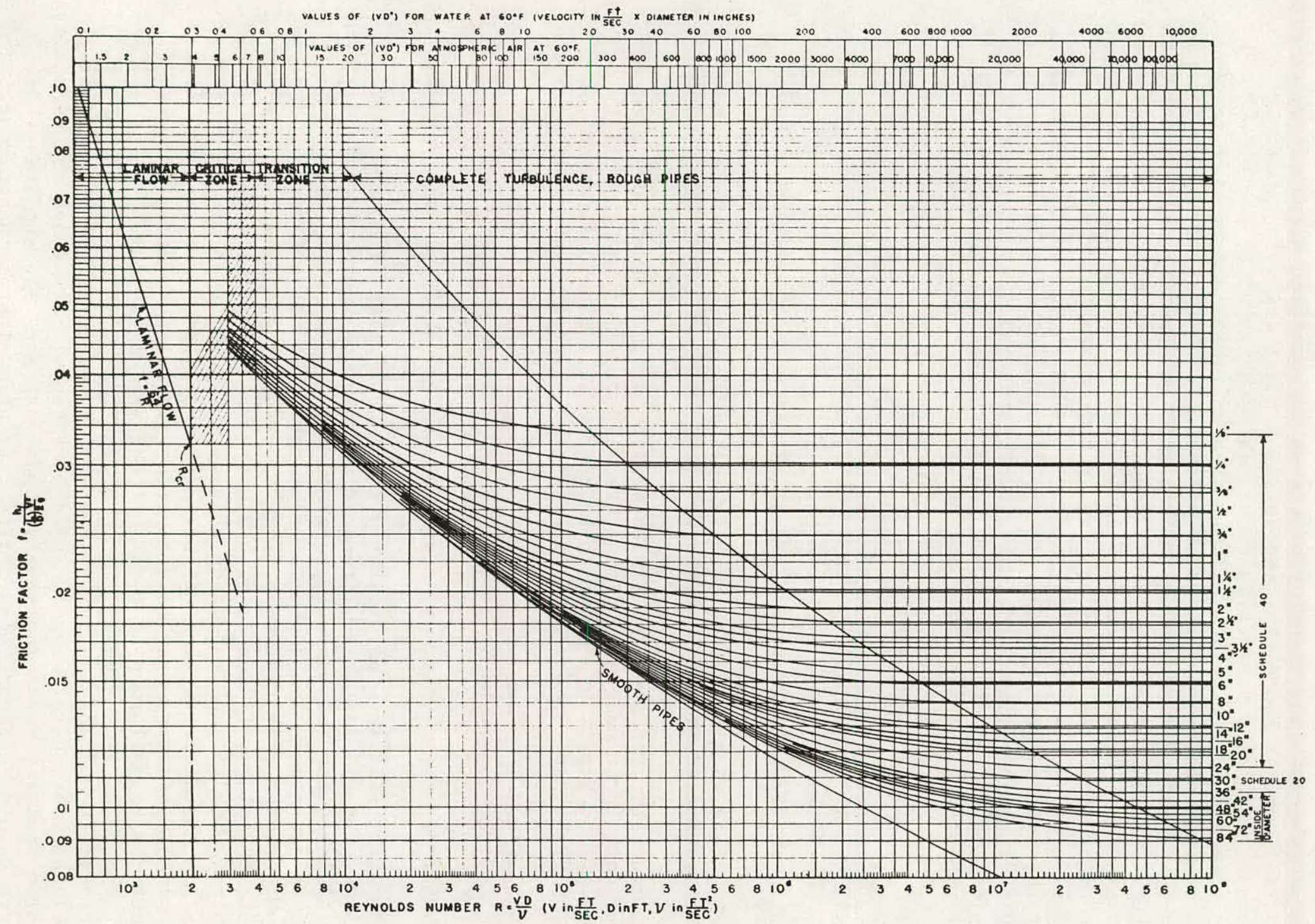

Figure 2-9. Pipe Friction Factors 
In the situation of vertical transport, the problem is much simpler. Upward movement will occur as long as the velocity of the carrier liquid is greater than the settling velocity of the solid particles being conveyed. Previous research has found that the solids concentration is almost uniform over a cross section of vertical pipe and that the velocity profile is only slightly affected by the solids. The most significant characteristic of vertical flow of slurry mixtures such as these is that the friction loss is computed like that of clear water, except that the density used is that of the mixture. Researchers (see Ref.8) have found that coarse particles which are randomly distributed at low velocities tend to move away from the pipe walls at high velocities. This results in an increase of the solids concentration at the center of the pipe while leaving a clear annulus of water at the walls. The presence of this clear annulus explains why the friction loss can be determined in the same manner as that of clear water. The simplest equation for calculating the friction loss encountered in vertical pipes $\left(h_{f v}\right.$ ) (see Refs. 4 and 8 ) is

$$
h_{f v}=f \frac{L}{D} \frac{V^{2}}{2 g}+\left(S_{W}-1\right) L
$$

where, $\mathrm{S}_{\mathrm{W}}=$ specific gravity of the mixture.

It is noted that the first term is identical to that used for the frictional resistance to flow of water.

Consequently, the pressure limitations of a slurry haulage system for conveying coal in an underground mine are a function of the capability of the pump industry to supply equipment which can satisfy the requirements of overcoming frictional losses and achieving the necessary vertical elevation changes while operating in the physical size contraints imposed by a given mine application.

\section{SUMMARY}

Coal-water slurries, particularly those consisting of homogeneous suspensions of small particles, frequently behave as non-Newtonian, Binghamplastic fluids. For successful operation, slurry transport systems should be designed to operate in the turbulent flow regime and at a flow rate at least 30 percent greater than the deposition velocity. The deposition velocity was defined as the slurry flow rate at which the solid particles tend to settle in the pipe. Due to the importance of accurately determining the deposition velocity and the uncertainties of current methods for predicting the deposition velocity of coarse particle slurries, it is recommended that experimental efforts be performed as a part of the system design.

The capacity of the haulage system should be compatible with the mine's projected coal output in order to avoid operational delays and the necessity for in-mine coal storage. The slurry pumps must generate sufficient discharge pressure to overcome the resultant friction losses in horizontal and vertical pipe sections and to satisfy the slurry hoisting requirements. 


\section{SECTION III}

\section{SUSPENSION PROPERTIES}

Prior to any discussion of the effects the solid particles have upon the characteristics of the mixture, it is useful to describe the manner in which the solids may be conveyed in a slurry suspension. Slurries are classified into three main categories: homogeneous, heterogeneous, and complex or compound.

The homogeneous slurries are defined as those which do not exhibit a measurable concentration gradient of solid particles when viewed along the vertical axis of a horizontal pipe. In other words, they possess a uniform distribution of solids and they do not separate from the liquid carrier even at very low flow velocities. They are generally characterized by a high concentration of solids which are of a fine size consist. Usually the viscosity of such a homogeneous slurry is significantly greater than that of the carrier liquid and this type of slurry often exhibits non-Newtonian flow behavior.

Heterogeneous slurries are those in which the solid particles and the carrier liquid maintain their independent identity. They are generally characterized by the presence of a lower solids concentration, consisting of larger particle sizes than homogeneous slurries, and they usually exhibit only a relatively small increase in the slurry viscosity over that of the carrier fluid. Any mechanism which describes the heterogeneous flow of suspensions must take into account the inertial effects of the particles themselves, and the influence of gravity upon the solids which induces settling. Particle interaction does have an influence on the settling of solids, but it is usually slight enough to be ignored. The significant factor is that the viscous and turbulent forces must be greater than the gravitational forces on the particles to prevent deposition. This type of flow is characterized by an identifiable solids concentration gradient along the vertical axis of a horizontal pipe. This phenomenon becomes less pronounced at higher velocities of flow and the slurry tends to operate towards homogeneity, although never fully achieving it. As the flow velocity is decreased, the maldistribution of solids becomes more pronounced until, at some value of flow velocity, a stationary layer or sliding bed of particles is distributed on the bottom of the pipe. The flow velocity at which this occurs is the deposition velocity which was discussed in Section II A.

The third category of slurry flow is usually referred to as a complex or compound system. This is a most important type of slurry flow since it is usually encountered in systems which are used to transport a solid material that is made up of a wide range of particle sizes. In such a complex slurry, the finer particle size-fractions join with the carrier liquid to form a homogeneous, non-Newtonian slurry vehicle in which the coarse size-fractions are suspended heterogeneously. A coal-water slurry is a prime example of this behavior. The exact characterization of this type of slurry flow is largely dependent upon the solids concentration, proportion of coarse and fine sizes, and flow velocity of the slurry.

Figure 3-1 illustrates the distribution of solids that will be experienced for the previously mentioned categories of slurry flow regimes. 


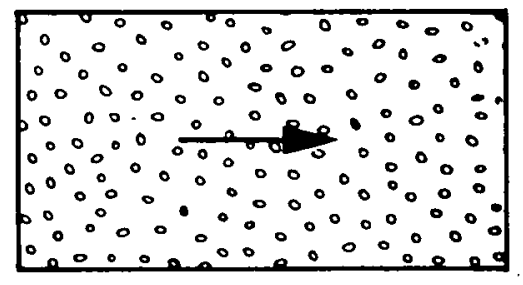

\section{HOMOGENEOUS}

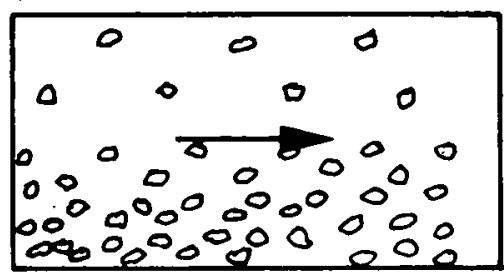

HETEROGENEOUS

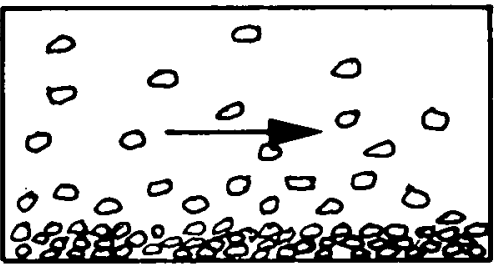

SLIDING BED

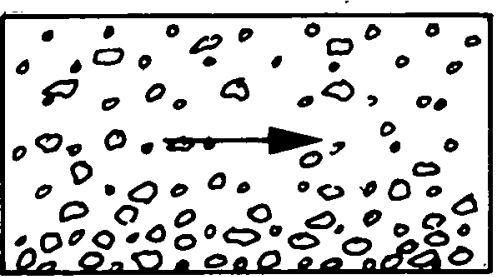

COMPOUND OR.COMPLEX

Figure 3-1. Slurry Flow Regime Particle Distribution 
Aude (Ref. 10) has presented one means of classifying slurry flow type as a function of its solids top-size (coarsest $5 \%$ ) and specific gravity. This method of categorization is shown in Figure 3-2 and it includes several assumptions. The assumptions which are incorporated in this means of classification are as follows:

(1) Most slurries with a low solids concentration will exhibit heterogeneous or complex characteristics unless the solids are extremely fine.

(2) At very high solids concentration, the slurries will tend to lose the heterogeneous or complex flow characteristics.

(3) The flow velocity is assumed to be in the range of four to seven feet per second.

The assumption of low slurry flow velocity is reasonable for the systems concerned with the long distance transport of coal-water slurries which have a greater need to minimize equipment abrasion and pumping power requirements, but it is probably too low for coal mine haulage systems which deal with a larger size consist of particles and operate over a much shorter distance. Raising the slurry flow velocity would most likely have a minimal effect on the limiting particle top size at which a slurry becomes heterogeneous even though the degree of heterogeneity is reduced as the velocity is increased.

Now that we have become cognizant of the three basic categories of slurry flow, we will discuss some of the parameters which are required for characterization of the flow and are collectively responsible for determining the slurry rheology.

\section{A. PARTICLE SIZE}

As was previously mentioned, the larger the particle size of the solids which are being conveyed in the slurry, the higher the flow velocity which is required in the system in order to control settling. Likewise, as the particle size and, subsequently, the slurry flow velocity increase, so. do the associated pump discharge pressure and power requirements.

For coal-water slurry haulage systems, a balance must be made between the particle size range of solids which are suitable for pumping and the size range which give good dewatering characteristics. If the size range is too fine, pumpability of the slurry may be good but the coal may be difficult to dewater. Furthermore, when considering mine haulage systems it is obviously desirable to minimize the crushing equipment requirements which are necessary at the coal seam face. If the size range of the solids is too coarse, a highly heterogeneous slurry can be expected with consequent higher flow velocity requirements and higher wear rates for the pumps and pipe. The ultimate choice of the particle size range depends upon:

(1) The overall cost of the preparation, pumping, and utilization of the slurry.

(2) The operability of the slurry system, including shutdown/startup characteristics and critical flow velocity. 


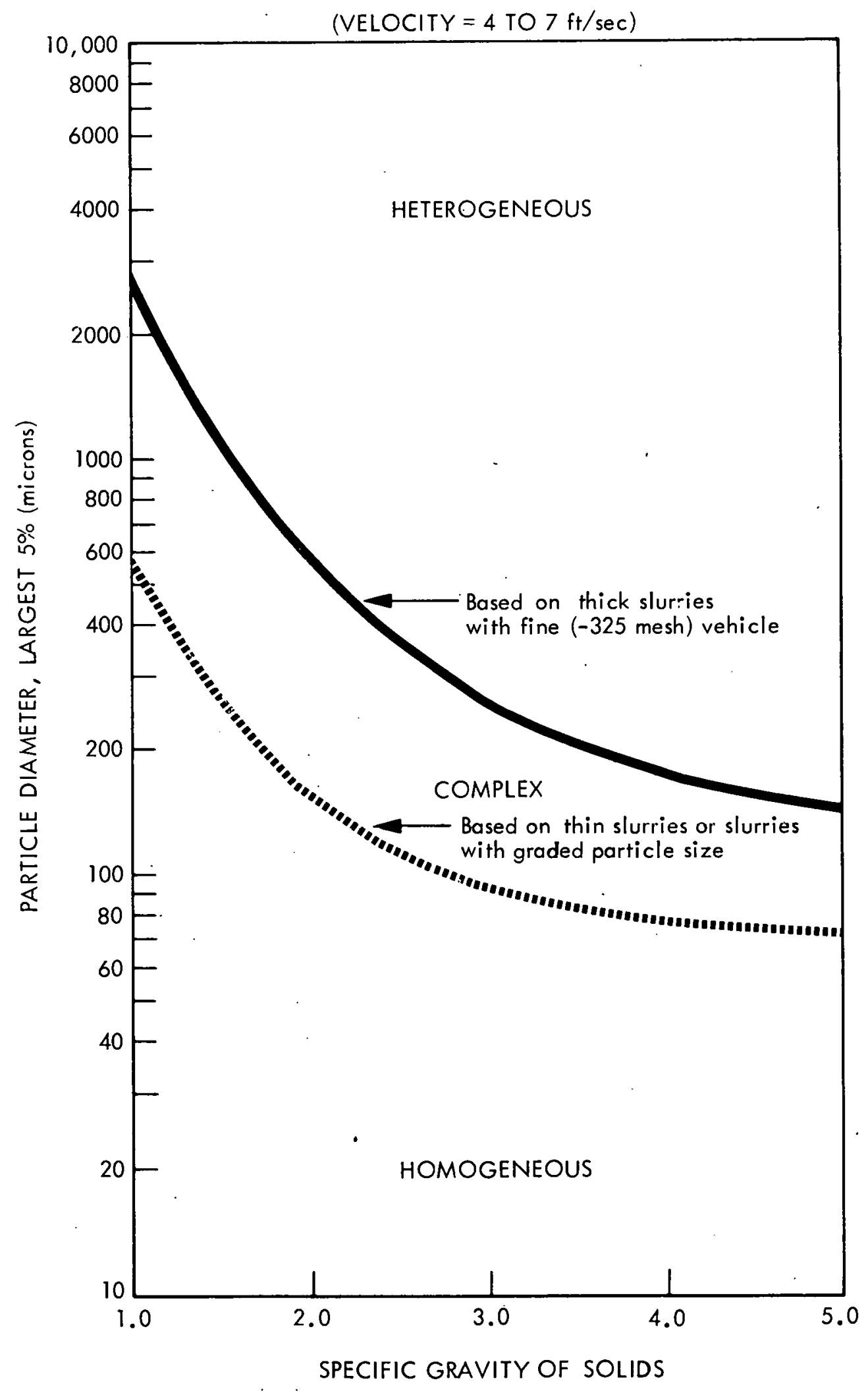

Figure 3-2. Slurry Flow Classification 
One of the most obvious performance limitations is the maximum particle size which may be passed through the pumping equipment without becoming lodged. It appears that a 4- to 6-in. diameter sphere is currently the largest particle size that can be passed through available centrifugal pumps. In regard to the maximum particle size, it should be noted that:

(1) This allowable maximum particle size refers only to the larger capacity pumps (approximately 6,000 , to $10,000 \mathrm{gal} / \mathrm{min}$ ) and would be less for smaller pumps.

(2) The slurry would consist of only a limited number of particles this large, and the normal size consist would probably have an average particle size of $1 / 4-$ to $1 / 2-i n$. diameter.

The slurry system consisting of such a large particle top size would not be appropriate for long distance transport since a sliding bed of particles would most certainly exist on the bottom of the horizontal pipe runs. However, for mine haulage systems, it could be practical to rotate the pipe at regular intervals in order to extend its service life which would be affected by the erosion caused by this sliding bed of particles.

An additional limitation on the system is that it is usually considered good engineering practice when dealing with slurry transport to limit the diameter of largest particle size being conveyed to one third of the minimum inside diameter of the pipe in which it is being carried. This guideline exists to minimize the possibility of plugging the pipeline.

\section{B. SOLID CONCENTRATION}

For most slurry haulage applications, it is normally preferable to convey the solids at as high a rate of concentration as is possible since this diminishes the use of water and lessens the return water pumping requirements. Furthermore, it results in a reduction in the size of the pumps, pipelines, and motors which are required for a given solids production rate.

As the solids concentration increases and/or the flow velocity of the slurry decreases, settling or deposition of the solids phase of the mixture increases and the solids concentration profile becomes increasingly asymetric.

It is often found to be convenient to express the solids concentration of a slurry mixture in terms of percent solids by weight $\left(c_{w}\right)$. This is particularly true when one is concerned with tonnage throughput of solids such as for mine haulage applications and for evaluation of the pumping energy requirements. However, the fluid mechanics of pipeline flow are more directly related to the volume concentration of solids $\left(C_{v}\right)$ which are present in the slurry mixture. Figure 3-3 depicts the relationship between the volume and weight concentrations of coal in a typical coal-water slurry. For most coal-water slurry applications, a concentration of $50 \%$ solids by weight or approximately $40 \%$ solids by volume is generally considered to be the maximum limitation for satisfactory operation (see Ref. 7). 


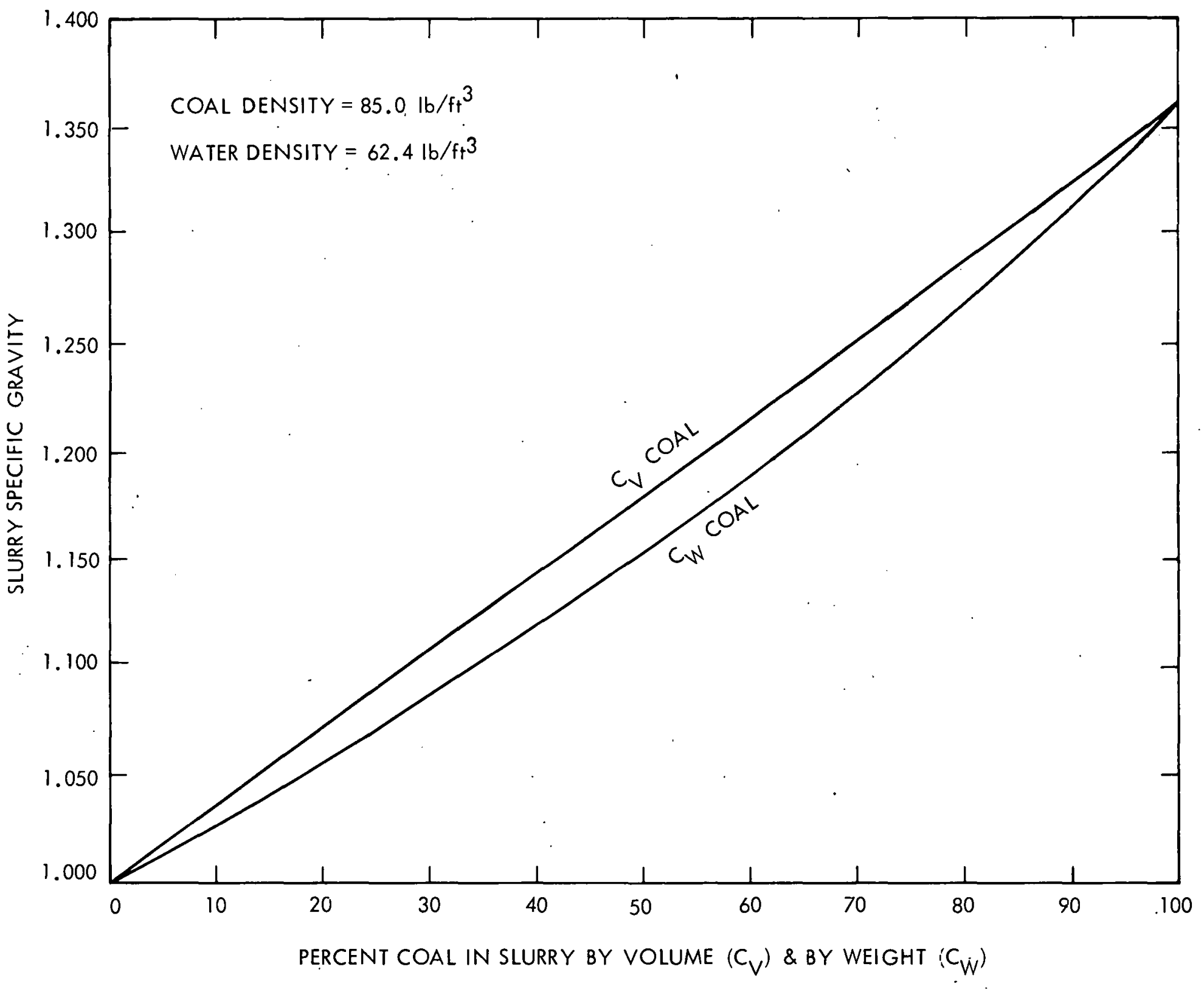

Figure 3-3. Solids Concentration by Weight and Volume 


\section{DENSITY}

There are three different density terms which are required for the complete description of any suspension. These three entities are (1) the density of the solid particles, (2) the density of the carrier liquid, and (3) the density of the slurry mixture.

When small solid particles are homogeneously suspended in a liquid, the mixture behaves as a fluid and the solid particles behave as though they are liquid portions of that fluid. However, there are some difficulties involved in directly measuring the slurry mixture density using conventional means such as the specific gravity bottle technique. Higher values of slurry density will be obtained than actually exist if solids have been allowed to settle and are not suspended in the liquid.

It is more reliable to express the density of a slurry suspension in terms of its component particle and liquid densities for a given concentration of solids, as follows:

$$
\rho_{\mathrm{m}}=\frac{100}{\frac{\mathrm{C}_{\mathrm{w}}}{\rho_{\mathrm{s}}}+\frac{100-\mathrm{C}_{\mathrm{w}}}{\rho_{1}}}
$$

where, $\rho_{m}=$ density of slurry mixture,

$$
\begin{aligned}
& \rho_{\mathrm{S}}=\text { density of solids, } \\
& \rho_{1}=\text { density of carrier liquid, and } \\
& \mathrm{C}_{\mathrm{w}}=\text { concentration of solids in percent by weight. }
\end{aligned}
$$

For solid particles of an identical size but of differing densities, those solids of a greater density or weight would be more susceptible to the gravitational and inertial effects present, and, hence, be more likely to experience settling at a given velocity of flow.

\section{VISCOSITY}

The presence of solid particles invariably increases the suspension viscosity to a value greater than the viscosity of the carrier fluid itself and, in many cases, the result is a slurry suspension which is non-Newtonian in behavior. The size and shape of the solid particles, as well as the solids concentration, are the principle factors, which have a relationship to the slurry viscosity. Suspensions consisting of fairly symetrically shaped solid particles, which are 50 microns or larger in diameter, tend to possess Newtonian flow characterisitics and exhibit a viscosity which is primarily a function of the volume concentration of solids. Suspensions of smaller sized particles or of asymetrically shaped solid particles frequently tend to exhibit non-Newtonian rheology (see Ref. 3).

It is usually the situation, that for slurries containing up to approximately a $30 \%$ concentration of solids by weight, there is a relatively 
minor increase of the mixture viscosity over the viscosity of the carrier fluid. As the concentration of solids in the slurry mixture exceeds $30 \%$ by weight, the mixture viscosity increases rapidly and has a significant effect upon the performance of the pumping equipment. This aspect of slurry pump performance will be dealt with in Section IV A.

Thomas (Ref. 11) presented an equation for the determination of slurry viscosity which is a function of the volumetric concentration of solids in the slurry:

$$
\frac{\mu_{\mathrm{m}}}{\mu_{\mathrm{o}}}=1+2.5 \mathrm{C}_{\mathrm{v}}+10.05 \mathrm{C}_{\mathrm{v}}^{2}+\mathrm{A} \exp \left(\mathrm{BC}_{\mathrm{v}}\right)
$$

where, $\mu_{\mathrm{m}}=$ slurry mixture viscosity,

$$
\begin{aligned}
\mu_{0} & =1 \text { iquid carrier viscosity, } \\
C_{\mathbf{v}} & =\text { volume concentration of solids, } \\
A & =\text { adjustable constant }=0.00273, \text { and } \\
B & =\text { adjustable constant }=16.6 .
\end{aligned}
$$

The values of $A$ and $B$, the adjustable constants, were varied by Thomas (see Ref. 11) to correlate with existing empirical data, and a 0.152 variance of fit was obtained using the values shown above. A plot of the relative viscosity $\left(\mu_{\mathrm{m}} / \mu_{\mathrm{o}}\right)$ as determined by Thomas' equation versus the volumetric concentration of solids in a slurry mixture is presented in Figure 3-4.

\section{E. SUMMARY}

Small coal particles tend to form a homogeneous mixture with the water which heterogeneously conveys the larger size solids. This is referred to as a compound or complex slurry. It is preferable for the slurry to accommodate the largest size coal particles possible in order to minimize the need for crushing equipment at the coal seam face. However, as the solids particle size increases, the minimum acceptable slurry flow rate, pump discharge pressure, and power requirements also increase. The maximum particle size of coal which can be successfully conveyed in a slurry transport system is approximately 4 in. in diameter.

It is also desirable to convey the coal in a slurry with as high a concentration of solids as possible since this reduces the water requirements and the size of the equipment (i.e., pumps, pipe, etc.) necessary for a given solids throughput. As the solids concentration increases, the slurry flow rate must also increase to overcome the tendency of the particles to settle. Existing technology currently limits the concentration of solids to a maximum of approximately $50 \%$ by weight. The density of the slurry mixture is a 
function of the individual densities of the solids and liquid of which it is composed and can be calculated if the concentration by weight of each is known. The presence of the solid particles in a slurry increases the suspension viscosity to a value greater than the liquid viscosity. This effect of the solids on the viscosity of the mixture is relatively minor, up to a concentration of approximately $30 \%$ solids by weight:

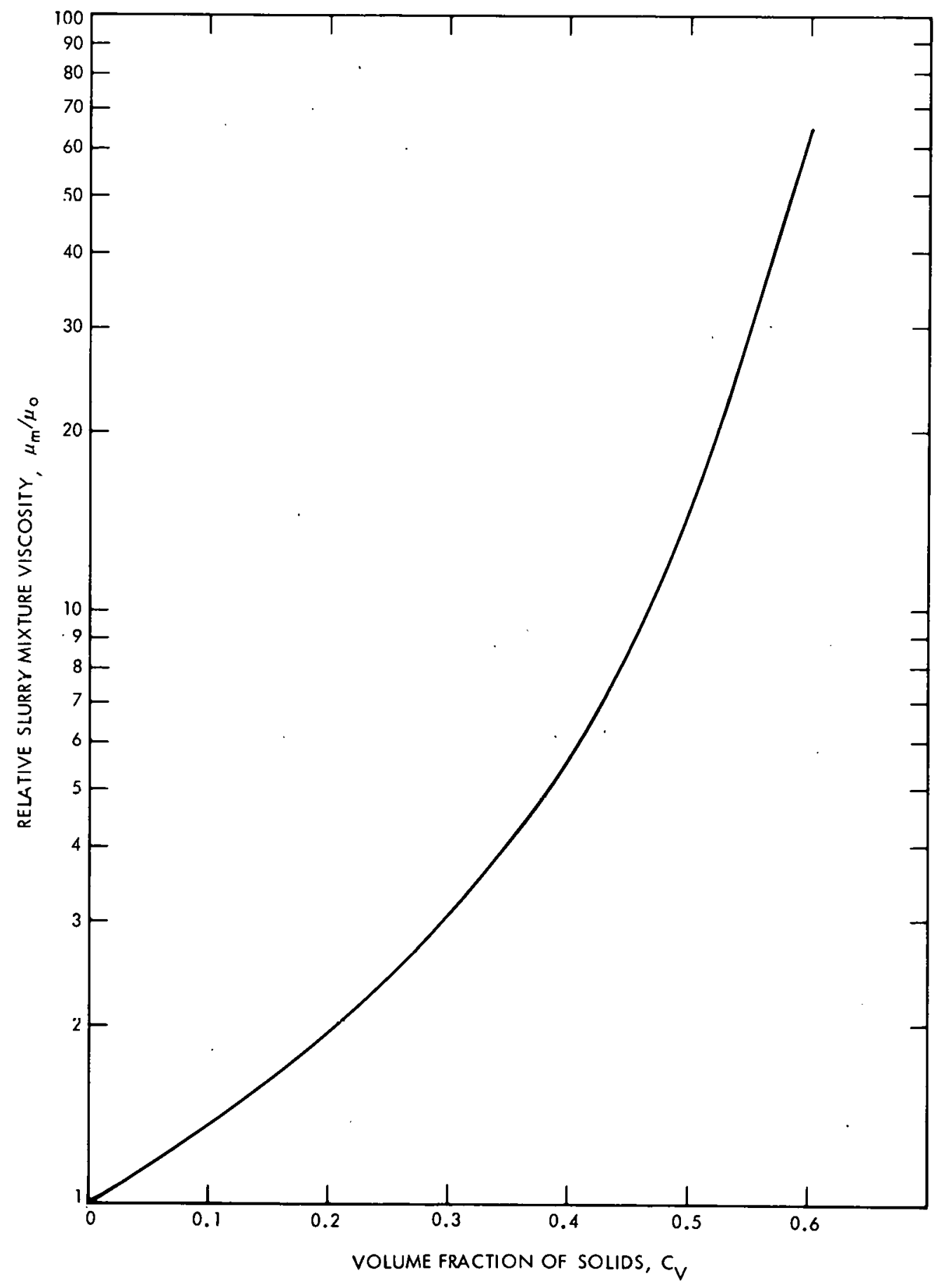

Figure 3-4. Relative Viscosity as a Function of Solids Concentration 
THIS PAGE

WAS INTENTIONALLY LEFT BLANK

$3-10$ 


\section{SECTION IV}

\section{EQUIPMENT AND OPERATION}

The design of a slurry haulage system for the purpose of transporting mined coal from the seam face out of the mine requires, at a minimum, equipment to perform the following functions. A feederbreaker is necessary to crush the coal from the mining machine to a size which is compatible with the capabilities of the hydraulic components of the haulage system. Pumps are used both to overcome the friction losses which are present in any hydraulic system and to satisfy the lift requirements which are mandated by the elevation difference between the coal seam face and the desired delivery point for the coal slurry. The slurry is conveyed in pipes with their attendant valves and miscellaneous hardware.

This presentation will limit itself to a brief discussion of the primary hydraulic components of the system, namely the pumps and piping. For our purpose, we will assume that the coal is supplied in a satisfactory particle size consist and provisions have been made to introduce it into the hydraulic system.

In addition to satisfying the slurry haulage system requirements, there are other equally important considerations regarding the mechanical equipment. Safety is of prime importance, and the operation of the equipment must be such that it functions in a nonhazardous manner and does not create a hazardous situation in the event of failure. The reliability of such a slurry haulage system is a significant factor, as it is with any pipeline transportation system, and its advantages over more conventional transportation schemes are rapidly diminished if the system is not reliable. The third factor, which is of paramount importance when designing a slurry haulage system for the underground transport of coal, is consideration of the equipment size constraints which are imposed upon the system components as a result of the mine environment and its limitations.

\section{A. PUMPS}

The pumps which are utilized for slurry transportation may generally be categorized by two generic types. These classifications are centrifugal and positive displacement pumps, and each type has certain advantages over the other which, depending upon the specific application, usually determines which is the more suitable type. Generally speaking, centrifugal pumps are capable of handling quite high rates of flow but at a discharge pressure less than the positive displacement units. The centrifugals also have the ability of pumping a slurry with a maximum allowable particle size that is considerably greater than the positive displacement can transmit. This attribute is considered significant for mine haulage systems since the reduction or elimination of crushing operations performed on the coal in the mine prior to its introduction in the slurry is an important factor.

The maximum size of solid particles which can be handled by centrifugal pumps is usually determined by dropping spheres of graduated sizes through 
the passages of the pump impeller and volute. This procedure will ascertain the maximum size sphere which can be passed through the pump without becoming lodged, but in no way implies an optimum size consist for hydraulic operation. Due to the reduced passages which exist in positive displacement pumps as a result of their inherent tight valve seating configurations and close tolerances, more severe limitations exist regarding particle size transmission. However, the positive displacement pumps have the capability of generating very high discharge pressures and usually operate at a higher efficiency than the centrifugals at the hydraulic conditions typical of slurry haulage applications. Consequently, positive displacement pumps are excellent for high pressure applications such as providing the driving force for pipe feeders or lockhoppers to obtain large vertical hoists. Tabulation of the performance limitations which apply to both centrifugal and positive displacement pumps is shown in Table 4-1.

Centrifugal pumps are usually chosen for underground haulage systems and for moderate vertical hoist requirements due to their ability to handle large particles and their smaller equipment size. The centrifugal pump is a very adaptable piece of mechanical equipment. Provided sufficient power has been included in the driver, it is possible to vary the head-capacity performance of the pump as a function of its rotational speed. The relationships which govern its operation are as follows:

$$
\begin{aligned}
& \frac{\mathrm{Q}_{1}}{\mathrm{Q}_{2}}=\frac{\mathrm{RPM}_{1}}{\mathrm{RPM}_{2}} \\
& \frac{\mathrm{H}_{1}}{\mathrm{H}_{2}}=\frac{\left(\mathrm{RPM}_{1}\right)^{2}}{\left(\mathrm{RPM}_{2}\right)^{2}} \\
& \frac{\mathrm{HP}_{1}}{\frac{\mathrm{HP}_{2}}{2}}=\frac{\left(\mathrm{RPM}_{1}\right)^{3}}{\left(\mathrm{RPM}_{2}\right)^{3}}
\end{aligned}
$$

where, $Q$ = capacity or flow rate,

$\mathrm{H}=$ discharge pressure or head,

$\mathrm{HP}=$ horsepower, and

$R P M=$ rotational speed of pump.

In the previous equations, subscript 1 designates the values of the flow parameters which exist at the original pump rotational speed, $\mathrm{RPM}_{1}$. Subscript 2 signifies the modified values of pump capacity, head, and horsepower that result from operating the pump at some new rotational speed, $\mathrm{RPM}_{2}$. These operational characteristics of a centrifugal pump can be quite advantageous when the driver is a variable speed unit. With such equipment, the flow rate of a system can be maintained that provides adequate slurry velocity if the system head curve varies. A centrifugal pump always operates at the intersection of its head-capacity or performance curve with the system head curve. The system head curve represents the head or pressure which is necessary to cause the flow through a system of piping, valves, etc. at various flow rates. A typical system head curve consists of three components: 
Table 4-1. Slurry Pump Performance Limitations*

\begin{tabular}{lcccc}
\hline $\begin{array}{c}\text { Maximum } \\
\text { Pump } \\
\text { Type }\end{array}$ & $\begin{array}{c}\text { Discharge } \\
\text { Pressure, } \\
\text { (psi.) }\end{array}$ & $\begin{array}{c}\text { Maximum } \\
\text { Flow, } \\
(\text { U.S. gpm) }\end{array}$ & $\begin{array}{c}\text { Mechanical } \\
\text { Efficiency, } \\
(\%)\end{array}$ & $\begin{array}{c}\text { Maximum } \\
\text { Particle } \\
\text { Size }\end{array}$ \\
\hline $\begin{array}{l}\text { Plunger } \\
\text { Piston }\end{array}$ & $3,500-4,000$ & 1,000 & $85-90$ & 0.094 in. \\
Centrifugal & $2,500-3,000$ & 3,000 & $85-90$ & 0.094 in. \\
\end{tabular}

*Reference 10

(1) Static head, defined as the head which is necessary to overcome elevation differences.

(2) Pressure head, representing the desired discharge pressure or head required at the outlet of the system.

(3) All losses; i.e., friction, entrance, and exit losses which result from the presence of piping, valves, and fittings and are a function of the flow rate.

To illustrate, reference is made to Figure 4-1 where the normal operation is shown as point 1 for the system as it was designed. If, however, the system head curve is modified by wear or the addition of extra pipe, then the modified system head curve would force the unit running at $\mathrm{RPM}_{1}$ to now operate at point 2. If this corresponding capacity, $Q_{2}$, is too low, then deposition of solids could occur as the velocity of flow is decreased by the reduction in capacity. By using a variable speed drive, it is possible to increase the centrifugal pump rotation and raise the head-capacity curve to some new level as shown by the $\mathrm{RPM}_{2}$ curve. In this situation, the pump would now operate at point 3 and the flow velocity would be increased to an acceptable value.

For the in-mine applications of a coal. slurry haulage system, centrifugal pumps are better suited to satisfy the equipment size limitations, which are imposed by the mining constraints, than the positive displacement pumps, which are, as a rule, substantially larger pieces of equipment for an equivalent volumetric capacity. That, coupled with their capability to handle slurries composed of large particle sizes and the lower installed capital cost which they possess as compared to positive displacement pumps, make centrifugal pumps the natural choice for an underground mine coal slurry haulage system. 


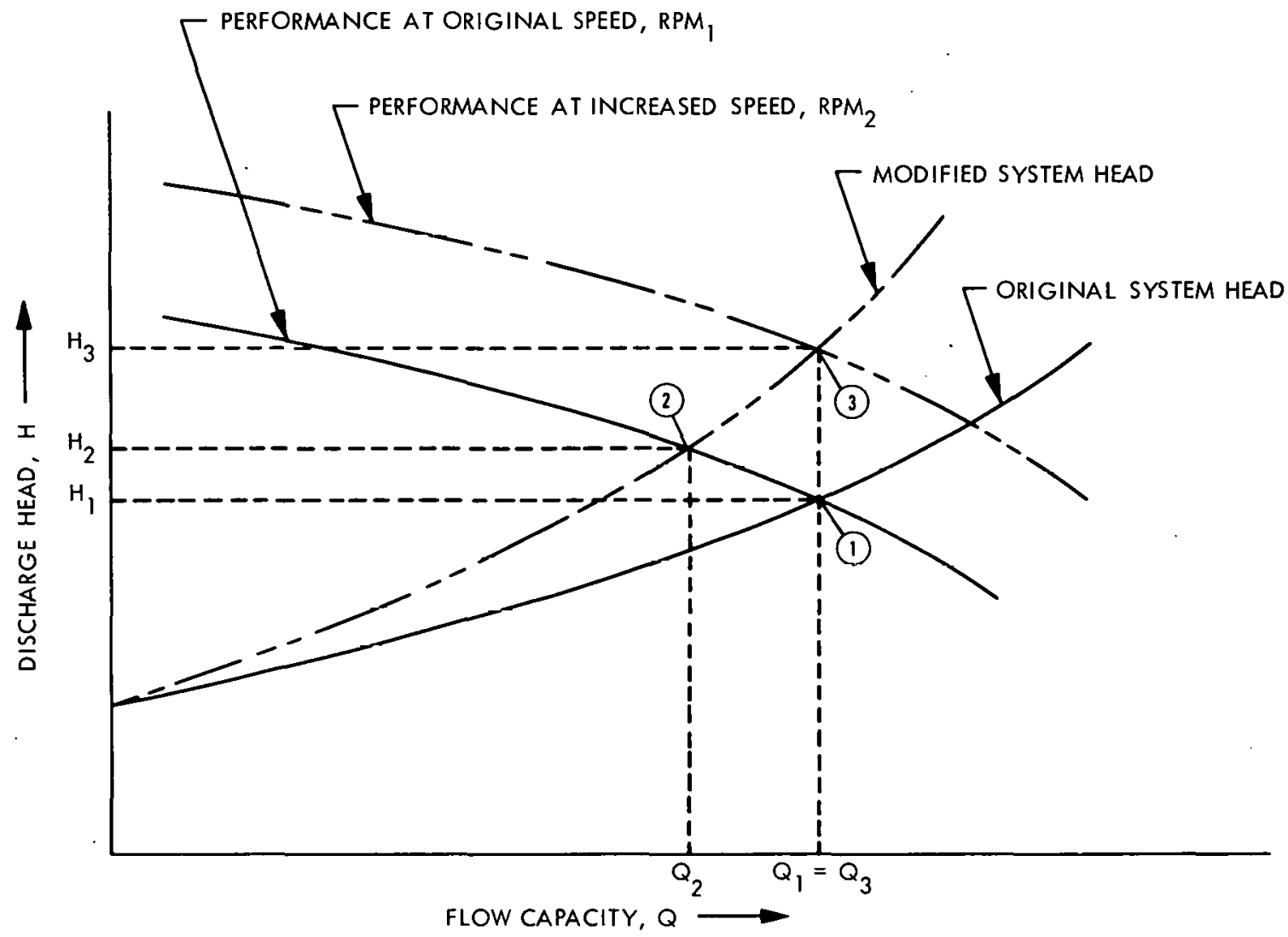

Figure 4-1. Variable Speed Centrifugal Pump Performance

The suspension property variables which have been found to have the greatest effect upon the hydraulic performance of centrifugal slurry pumps are particle size, specific gravity, and concentration of the solids contained within the slurry mixture. The presence of solids in a slurry suspension unfavorably affects both head or discharge pressure developed and power consumed by the pump. These adverse effects can primarily be attributed to:

(1) The presence of slip between the carrier liquid and the solid particles being conveyed which occurs, particularly during acceleration and deceleration of the slurry, as a result of the pump operation.

(2) The elevated viscosity of the slurry mixture which has a tendency to lower the head developed by the pump and reduce its hydraulic efficiency.

Abrasion which is experienced in solids-handling pump applications can be categorized by three different types:

(1) Gouging - coarse particles impinge with sufficient force to cause high impact stresses. 
(2) Grinding - particles are crushed between two moving surfaces.

(3) Erosion - free-moving particles impinge on the wearing surface.

Experience has shown that for pumps handling slurry mixtures consisting of abrasive solids, the pump velocity should be kept as low as possible in order to minimize the resultant wear. It has been found that the pump wear is approximately proportional to the cube of the velocity (wear velocity ${ }^{3}$ ). Therefore, since the pump velocity is directly related to the pump developed pressure, it follows that pumps utilized for high head applications will generally wear more rapidly than similar units operating at a lower head service. Also, the wear is usually found to be inversely proportional to the hardenss (BHN) of the wetted pump components (wear $\alpha \frac{1}{\mathrm{BHN}}$ ) and wear normally varies directly with particle concentration (wear $\alpha \mathrm{C}_{\mathrm{v}}$ ).

In centrifugal pumps, unless the solid particles are quite fine, closed impellers are considered to be preferable to open construction impellers. Open impellers are those without a suction side shroud, whereas, closed impellers possess shrouds on both sides of the impeller vanes. Normally closed impellers are chosen because more uniform wear of the impeller flow passages results, closed impeller geometry provides a structurally stronger design, and closed impellers are less sensitive to increased clearance between the impeller, and the casing wall of the pump.

Natural and synthetic rubber is sometimes used to protect the pump's internal surfaces against wear if the solid particles of the slurry are small and relatively round. However, rubber liners or coatings are unsuitable if the solid particles are sharp and hard since they have a tendency to cut or tear the rubber. Rubber is generally not appropriate for applications with pumps having discharge heads in excess of $150 \mathrm{ft}$, peripheral impeller tip speeds in excess of approximately $5000 \mathrm{ft} / \mathrm{min}$, or if the solid particles in the slurry are greater than $1 / 4$ in. in diameter. Consequently, rubber lined slurry pumps are not considered a viable choice for a coal slurry mine hanlage system due to these limiations. For this type of service, pumps constructed of wear resistant materials such as $\mathrm{Ni}$-hard are found to be compatible with the application and useful for extending the life of the pumping equipment.

The previously discussed, conventinnal approach for satisfying the pumping requirements of an in-mine coal slurry haulage system consists of (1) mixing the coal and water in an open tank at the coal seam face, (2) pumping the mixture to the mine shaft, and (3) subsequently lifting it by pumping to the mine entrance. However, there are also several other concepts, some of which will be mentioned, for both forming the slurry and providing the pipeline pressure necessary to transport the mixture.

One of the most difficult tasks in the design of a face haulage subsystem due to the limitations resulting from the low headroom is the introduction of the coal into the pipeline. A concept currently under development is commonly referred to as a high pressure injection system. In such a design (Ref. 12), a combination crusher-injector would be used to 
inject the coarse coal particles into a high pressure stream of water. A diagram illustrating this approach is shown in Figure 4-2. Two significant advantages to such a concept are that:

(1) It could be feasible to utilize the substantial gravitational forces generated on the return water line of a closed system to provide the high pressure source for the jet injector.

(2) If pumps are used to generate the pressure for the jet injector, then the wear on the pumps would be substantially less than the conventional system since they would be handling only water and not a slurry mixture.

Such a design scheme provides an attractive alternative for the horizontal transporation of the coal from the seam face but would probably not be capable of generating sufficient head for vertical lifts to the mine entrance at the surface.

One approach for vertically hoisting the coal slurry from a deep mine is the lockhopper or pipe feeder system (see Refs. 3 and 8 ). This method would also separate the pumps that generate the necesssary high pressure from the abrasive slurry. An illustration of a lockhopper system is shown in Figure 4-3. Such a scheme would consist of two or more pressure vessels that are alternately charged with the slurry mixture and, in turn, injected with a high pressure flow of water. It is possible to utilize a lockhopper system to satisfy the slurry hoisting requirements from an underground mine where the pump is located on the surface and the pressure vessels and valves are in the mine. Once again, this arrangement would also gain the advantage of gravity to assist in generating the necessary pressure. The constraint upon the allowable particle size of coal which the pump could pass without plugging and the equipment size limitations imposed upon an in-mine pump application would not be a factor for consideration in such a system and it is possible that a positive displacement pump may be a more advantageous choice. It has been reported (see Ref. 8) that the lockhopper system can hydraulically lift coal with a particle size as great as $75 \%$ of the inside pipe diameter, but is recommended that the maximum particle size should not exceed $33 \%$ of the pipe diameter.

The costs for utilizing centrifugal pumps for vertical hoisting are substantially less than the lockhopper costs. However, when the vertical distance which the coal slurry must be lifted exceeds about $500 \mathrm{ft}$, consideration should be given to lockhopper and other alternative hoisting subsystems. This is because the large number of centrifugal pumps that would be required to operate in series would probably adversely affect the larger coal particles causing size degradation and producing excessive fines.

\section{B. PIPE AND VALVES}

The problem of wear which was discussed in the preceeding section on pumps handling slurry mixtures is also experienced in the piping system, but to a lesser degree than for pumps. For a given quantity of slurry throughput, 


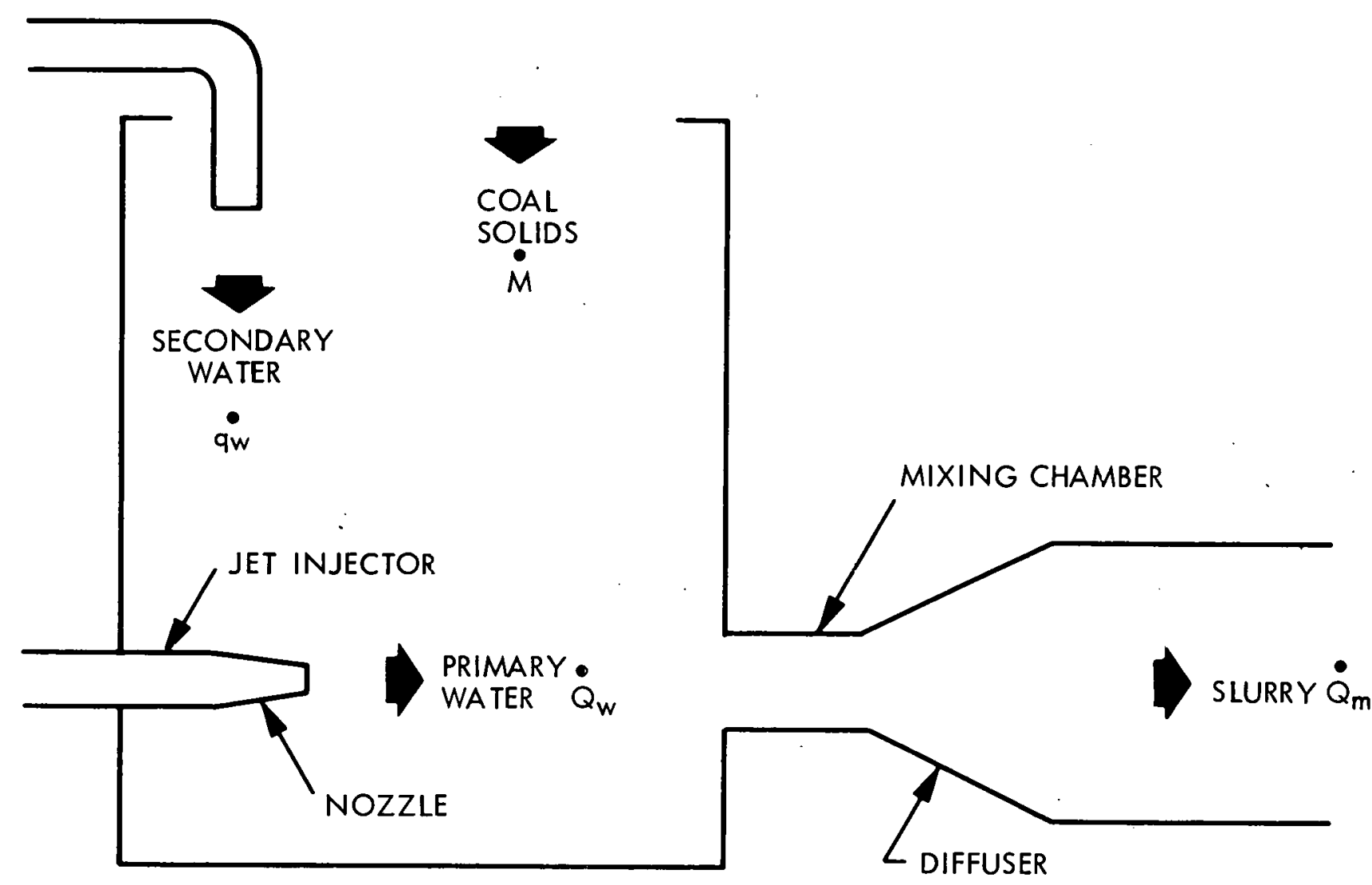

Figure 4-2. High Pressure Injection Scheme 


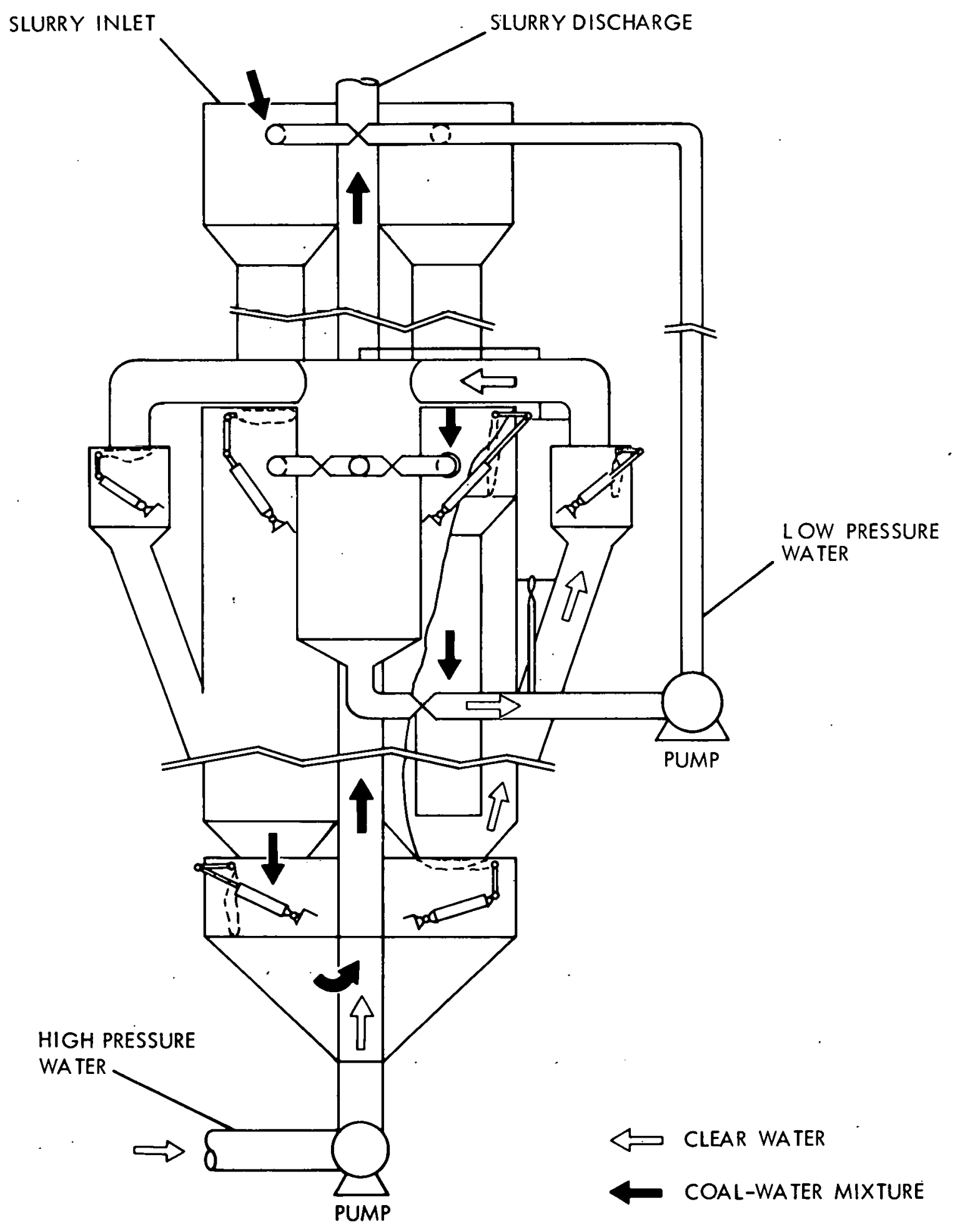

Figure 4-3. Lockhopper System Diagram 
the selection of the pipe diameter determines the transport velocity. Consequently, as the flow velocity of the mixture increases so does the erosion of the components and the resultant friction losses.

The abrasion which is experienced in the pipe can be categorized as either deformation wear caused by impact of the solid particles or cutting wear resulting from the sliding action of the solids. Abrasive wear is primarily governed by the following factors:

(1) Characteristics of solids - size and size distribution, hardness, density, shape, and composition.

(2) Characteristics of carrier liquid - corrosiveness, density, and viscosity.

(3) Condition of flow regime - laminar or turbulent, heterogeneous or homogeneous, and velocity.

(4) Pipe material - strength and ductility.

Homogeneous slurries normally can operate at velocities up to approximately $10 \mathrm{ft} / \mathrm{s}$ before pipe wear becomes an item of concern. However, for heterogeneous slurries, such as would be experienced in a coal slurry mine haulage system, the abrasive wear on the piping system can be severe at slurry flow velocities greater than $5 \mathrm{ft} / \mathrm{s}$, and the wear increases exponentially as approximately the cube of velocity.

One distinct advantage held by a mine slurry haulage system is that the accessibility and length of the pipe subjected to extreme wear conditions lends itself to periodic rotation of the pipe in order to extend its service life. This is a useful attribute of the system since the majority of the abrasive wear will be experienced on the bottom of the pipe as a result of the pronounced solids concentration gradient in the horizontal pipe runs. The pipe which is oriented in a vertical position to achieve the lifting of the slurry mixture can have a lesser. wall thickness for wear allowance than the horizontal pipe due to the formation of the previously. discussed water annulus which will lead to a negligible abrasion loss.

Commercially available pipe of standard wall thicknesses is capable of containing the anticipated slurry pipeline operating pressures. However, the determination of the particular pipe grade, necessary wall thickness, and desired corrosion/erosion allowance must be evaluated for each specific application. Good design practice suggests that in order to avoid operational problems in conventional systems caused by pipe blockage, the minimum inside diameter of the pipe used for slurry transport should be at least three times as great as the diameter of the largest particle size being conveyed. Additionally, in order to minimize abrasive wear, it is recommended that the minimum radius used for fabricated pipe bends should be at least five times the pipe diameter and three times the pipe diameter for cast bends. While it is not always possible to adhere to these criteria, particularly at the seam face of the mine where rubber hose may be used to obtain the system flexibility necessary to follow the mining machine, it is always advisable to minimize abrupt changes in the direction of flow. 
The abrasive service under which the valves in the system must operate should also be given consideration. It is preferable that the valves possess a full line-size opening at the non-throttled position since restrictions in the valve will cause abrasion downstream. If possible, the valves should not contain recesses or voids that could collect solids and impair operation, nor should they be dependent upon finish machined-metal surfaces for sealing since these can rapidly deteriorate.

\section{INTERNATIONAL EXPERIENCE}

There has been a significant amount of activity by numerous countries in the area of hydraulic transport of solids in a mining environment. Canada, China, Czechoslovakia, France, West Germany, Japan, New Zealand, Poland, United Kingdom, the United States, and Russia have all had operating experience with hydraulic coal transport of either an experimental or production nature. All of these aforementioned instances relate directly to mine installations and not simply laboratory test facilities. There are over thirty applications of the use of hydraulic transport to satisfy one or more aspects of the coal haulage requirements associated with mining operations around the world. For instance, the Baydayevskaya-Severnaya-1 mine in the U.S.S.R. utilizes a slurry haulage system on the surface to convey the mined coal 32,800 ft. The Hansa mine in West Germany has two underground pipelines of $6,900 \mathrm{ft}$ and $10,500 \mathrm{ft}$ in length and a pipe feeder or lockhopper system to hoist the coal slurry $2,800 \mathrm{ft}$ vertically. Both of these applications are for production coal mine installations.

Many of the in-mine hydrotransport endeavors to date have been associated with hydraulic mining activities where a high pressure jet of water is used for the coal cutting function. This is commonly referred to as hydromining. Those countries involved in hydromining activities have also investigated the possibility of hydraulic transport of coal via gravity operated flumes where the water used for the solids extractions can also be used for the loading and transport of the coal (Ref. 13). However the majority of the international work in hydrotransport appears to have been involved with the development of hydraulic hoisting systems for the vertical conveyance of the mined coal (Ref. 14). While most of these efforts are concerned with the use of lockhopper or pipe feeder mechanisms, there have been significant achievements by China, West Germany, the United States and Russia in the use of pumps to directly satisfy the vertical lift requirements of conveying the coal/water slurry from the mine to the surface.

\section{SUMMARY}

For the in-mine applications of a coal slurry haulage system, centrifugal pumps are better suited to satisfy the equipment size limitations, which are imposed by the mining constraints, than the positive displacement pumps which are, as a rule, substantially larger pieces of equipment for an equivalent volumetric capacity. That, coupled with their capability to handle slurries composed of large particle sizes and the lower installed capital cost which they possess as compared to positive displacement pumps, makes centrifugal pumps the natural choice for an underground mine coal slurry haulage system. The most advantageous use of positive displacement 
pumps in a slurry haulage system may be for accomplishing the slurry hoisting requirements by supplying the high pressure fluid to a lockhopper or pipe feeder mechanism where the slurry is segregated from the pump and the positive displacement pump(s) may be located on the surface.

The abrasive wear experienced in slurry pumps, pipe, and valves is proportional to the cube of the flow velocity, inversely proportional to the material hardness of the components, and directly proportional to the volumetric concentration of solid particles conveyed. The strong influence that the slurry flow velocity has on the rate of wear tends to set the upper limit on the acceptable flow velocity relatively close to the mininum operating velocity. The minimum operating velocity was previously defined as at least $30 \%$ greater than the deposition velocity.

There continues to exist a definite need both to accumulate engineering design and operating data and to develop and test equipment. It is recognized that of the countries which are members of the International Energy Agency, there are currently extensive research and development activities being pursued in Canada, West Germany, United Kingdom, and the United States that are relevant to the underground hydraulic transport of coal (see Ref. 13). 
THIS PAGE

\section{WAS INTENTIONALLY LEFT BLANK}


SECTION $\mathrm{V}$

\section{SYSTEM PERFORMANCE}

Several benefits could be realized as a result of utilizing a slurry haulage system for the conveyance of coal in an underground mine. Among the possible advantages reported (see Refs. 1 and 5) of such a method, is the opportunity to more effectively utilize the production capability of existing continuous mining machines and to improve the continuity of the system's operation, thus increasing the mine's productivity. This would be accomplished by the elimination of the numerous transportation transfer points which currently exist in the conventional conveyor haulage subsystems and by reducing the continuous miner downtime as a result of the attendant delays. Previous reports by others (see Refs. 1 and 5) have contended that worker safety would be enhanced since the slurry haulage system would entrain the coal dust and gases, minimize occurrences of spillage, and reduce the quantity of hazardous moving parts and eqipment to which the miner is exposed. Furthermore, it may be possible to utilize a path more direct than that usually taken for the removal of coal from the mine by routing the slurry pipeline through small boreholes from tunnels or mine entries.

Review of the discussion in Sections II-IV reveal that the parameters which have the greatest effect upon limiting the performnce of the slurry haulage system are:

(1) Flow velocity.

(2) Pressure.

(3) Coal particle size.

(4) Solids concentration.

The velocity of the slurry must be high cnough to prevent excessive settling of solids and the subsequent plugging of the pipeline but, at the same time, be no greater than necessary in order to prevent excessive friction head losses and pipeline wear. For such a system as considered in this report, the optimum velocity of the slurry is expected to be from 10 to $15 \mathrm{ft} / \mathrm{s}$. Figures 5-1, 5-2, and 5-3 illustrate the performance envelopes of hydraulic transport systems operating within this velocity range utilizing nominal pipe sizes from 4 to 20 in. in diameter and conveying 30,40 , and $50 \%$ volumetric concentrations of coal respectively and $0 \%$ rock. Pipe sizes less than 4 in. in diameter would not be capable of transporting a great enough quantity of slurry to be practical, and pipe sizes much 1 arger than 20 in. in diameter are difficult to manage in an underground mine environment. The curve representing a slurry containing a $30 \%$ volumetric concentration of coal, Figure $5-1$, is well within the boundaries of existing design and operating capabilities. Figure 5-2, where $\mathrm{C}_{v}=40 \%$, illustrates the system performance that approximates the limits of current technology. Figure 5-3 depicts the anticipated output of a slurry haulage system if, as a result of technological innovations, the volumetric concentration of coal could be increased to $50 \%$. 


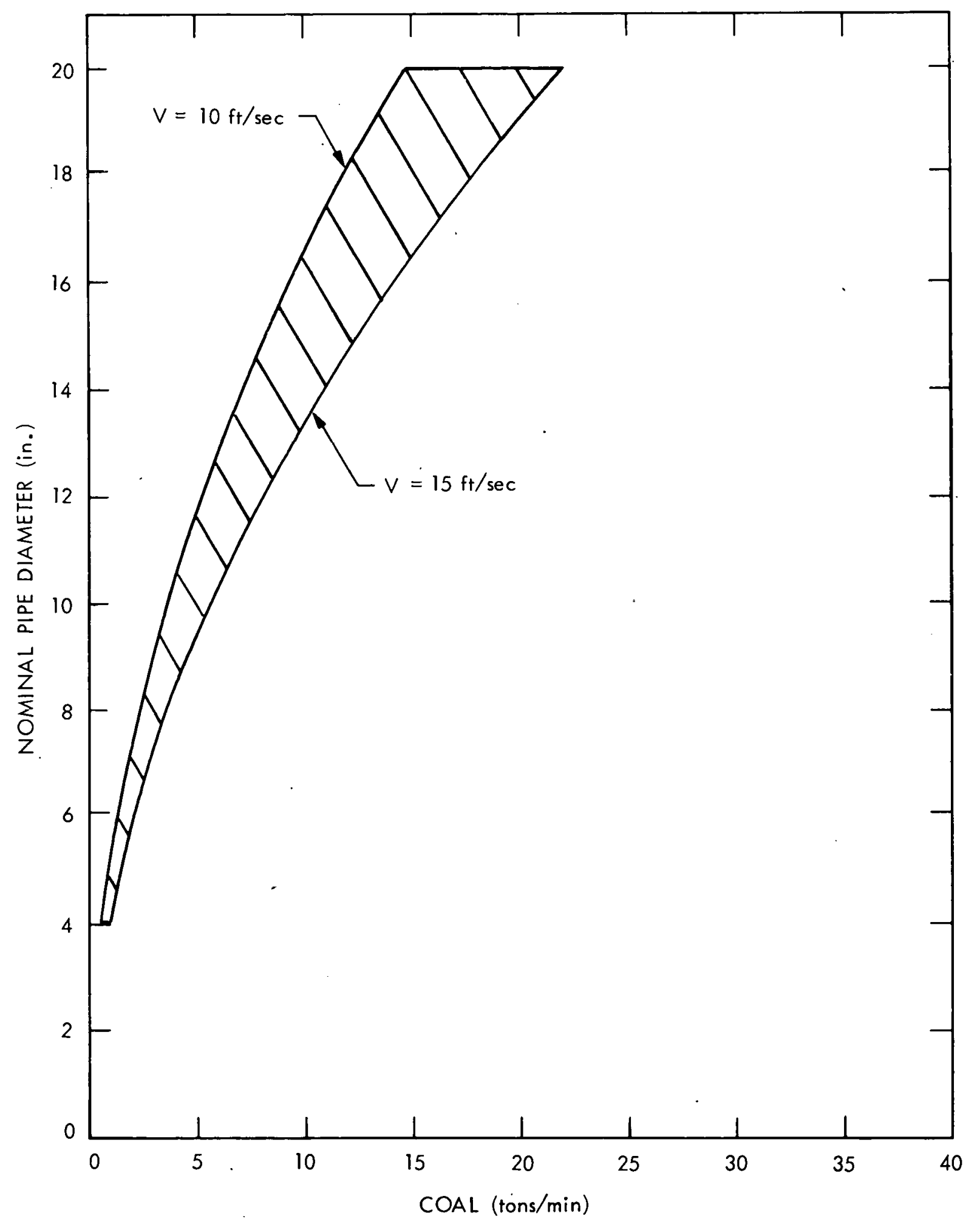

Figure 5-1. System Performance Envelope, $C_{v}=30 \%$ 


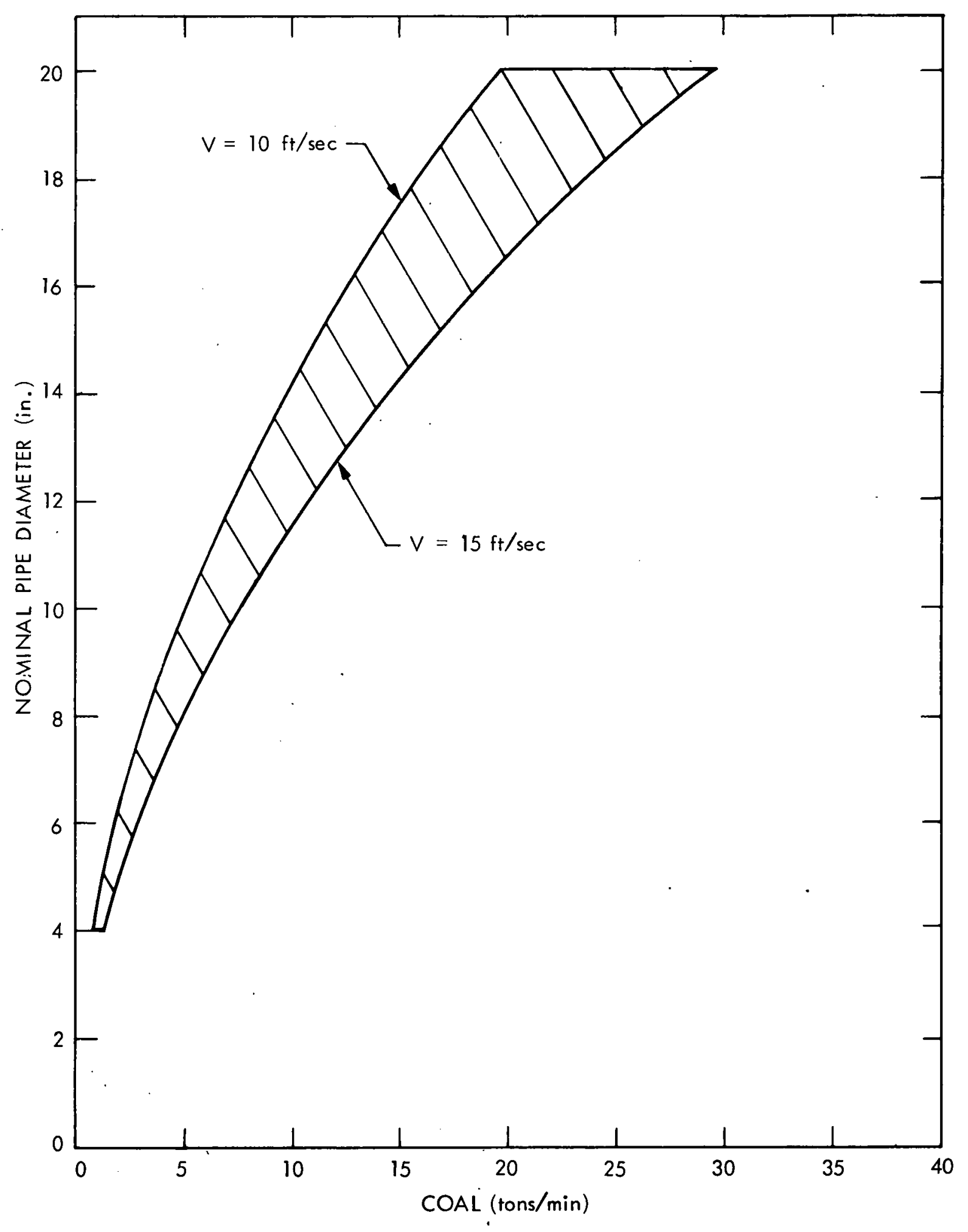

Figure 5-2. System Performance Envelope, $C_{v}=40 \%$. 


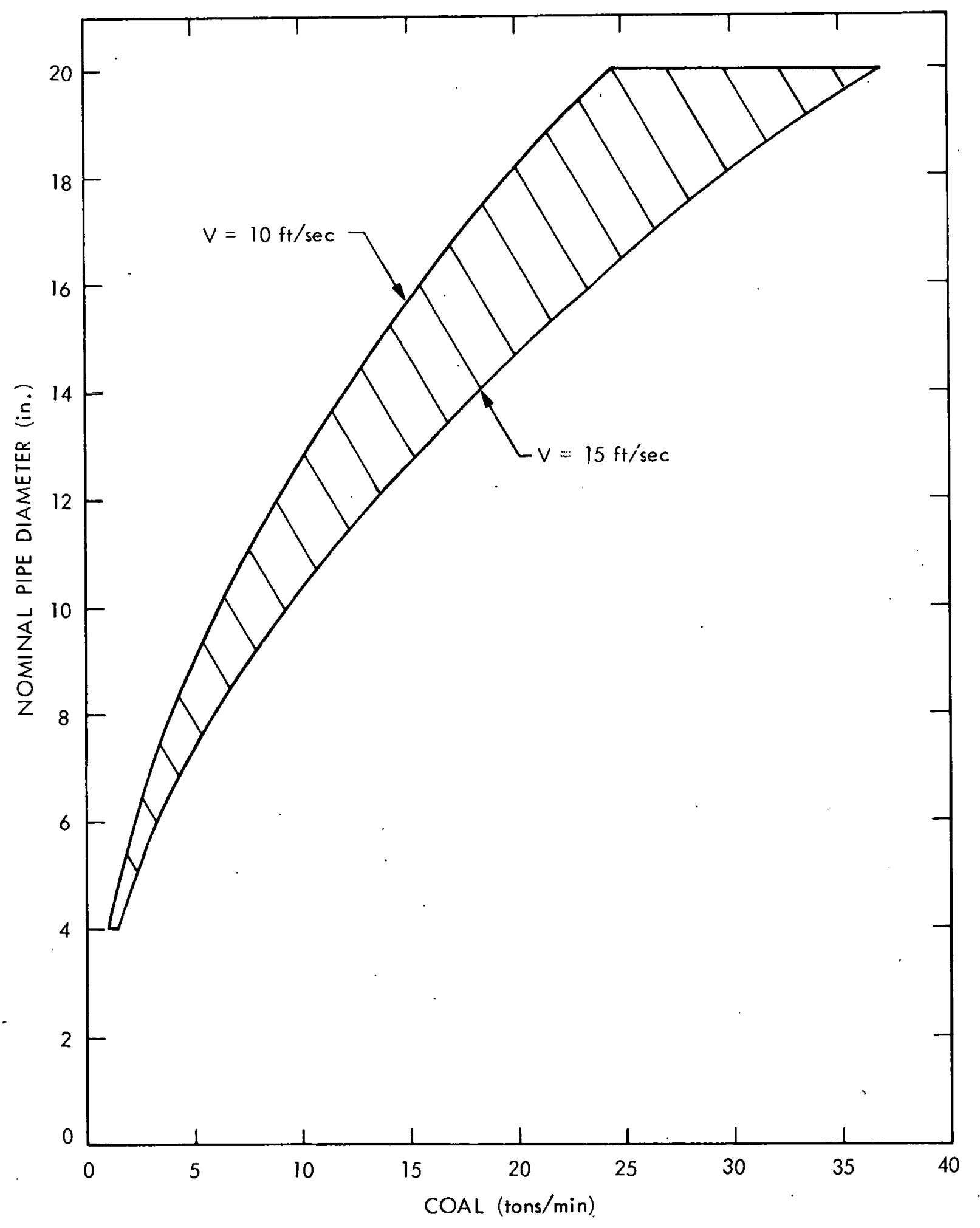

Figure 5-3. System Performance Envelope, $C_{v}=50 \%$ 
The operating pressure of the slurry system must be sufficient to overcome frictional losses and static lift requirements. The conveyance of coal from the seam face can normally be accomplished by 100 psi. of pressure, which is well within the capabilities of existing centrifugal pumps that also satisfy the capacity or flow rate requirements and size constraints imposed by an underground mining application. Centrifugal pumping equipment currently exists that can produce a discharge pressure of approximately 600 psi (1386 ft of water) to accommodate the vertical lift requirements for bringing the slurry to the surface. However, vertical hoists of greater than about $1000 \mathrm{ft}$ are usually not considered when using centrifugal pumps. This is due to the necessity of staging or operating a number of pumps in series which will result in excessive particle size degradation, the reduction of generated pump discharge pressure that occurs when pumping a slurry, and the presence of pipe friction losses that must be overcome.

It is most desirable to operate the haulage system with run-of-the-mine coal as it is produced by the continuous mining machine. However, it is necessary to process the coal through a breaker or crusher before introducing it into the slurry since the maximum allowable particle size currently appears to be approximately 4 in. in diameter. This limitation is primarily a function of the size of solids particles that can physically be passed through the pump, but a general guideline is that the maximum particle size should be no larger than one-third of the interior pipe diameter.

From practical considerations, it is obviously preferable to transport as great a concentration of solids in the slurry as possible. Previous experimental work by others has shown this limit to be approximately $40 \%$ coal by volume or about $48 \%$ coal by weight in a slurry with water.

While investigation (see Ref. 1 and Ref. 15) has been performed on the subject of coarse particle slurry transport, unfortunately the majority of the data is held as proprietary information by the private companies performing this research. The areas exhibiting the greatest need for further study are large particle slurry flow characterization and pipeline plugging phenomena. The work currently being performed under the U.S. Department of Energy sponsorship in their hydrotransport continuous face haulage subprogram (Ref. 16) is intended to satisfy the equipment development need for an improved method of solids injection so that pump wear is minimized.

A previous study (see Ref. 6) by others has concluded that, while the necessary capital investment for an in-mine hydraulic transport system is greater than for the conventional haulage system using shuttle cars and conveyor belts, the potential increase in coal production should result in a mine mouth cost of coal which is less. This report concluded that a mine utilizing a coal slurry haulage system, instead of the ordinary means of conveyance, will experience an approximately $40 \%$ increase in productivity. 
SECTION VI

REFERENCES

1. Poundstone, W. N., and Dahl, H. D., "Hydraulic Transportation of Coarse Coal Slurries," presented at A.I.M.E. meeting, March 10, 1977.

2. Ingersol1-Rand Company, Cameron Hydraulic Data, Fifteenth Edition, 1977.

3. Wasp E. J., Kenny, J. P., and Gandhi, R. L., Solid-Liquid Flow, Slurry Pipeline Transportation, Trans Tech Publications, 1977.

4. Durand, R., "The Hydraulic Transportation of Coal and Other Materials in Pipes," Colloquim of National Coal Board, London, November 1952.

5. Faddick, R. R., "A Mineral Slurry Data Bank: Part 1 Report," Colorado School of Mines, Bureau of Mines Report OFR 2(1)-73, December 2, 1972.

6. Link, J. M., Allan, A., and Faddick, R. R., "Feasibility of Hydraulic Transportation in Underground Coal Mines," Colorado School of Mines Research Institute, Bureau of Mines Report OFR 68-75, May 30, 1975.

7. McElvain, R. E., "High Pressure Pumping," Skillings Mining Review, January 26,1974 .

8. Hartman, R. A., and Reed, J. R., "Feasibility Study of the Vertical Transport of Coal by Pipeline," The Pennsylvania State University for the Commonwealth of. Pennsylvania, Special Research Report SR-97, September $30,1973$.

9. Hydraulic Institute, Pipe Friction Manual, Third Edition, 1975.

10. Aude, T. C., and Pitts, J. D., "Slurry Pipclinc Design-Materials and Equipment Selection," Proceedings of the International Technical Conference on Slurry Transportation, February 1976.

11. Thomas, D. G., "Transport Characteristics of Suspension: VIII. A Note on the Viscosity of Newtonian Suspensions of Uniform Spherical Particles," Journal of Colloid Science, 20, pp. 267-277, 1965.

12. Malsbury, R. G., Kermit, P., and Saad, A., "A Jet Pump Injector for Coarse Coal Face Hydraulic Haulage," presented at the 4th International Conference on Slurry Transportation, March 1979.

13. Gregory, F. W., "Hydrotransport of Solids Underground," Mining Technology Clearing House Report MTCH-TI-1.1, December 1977.

14. Miscoe, A. J., "Hydraulic Transportation for Coal Mining," presented at U.S./D.O.T. Workshop on Materials. Handling for Tunnel Construction, August 1977. 
15 Dah1, H. D., and Petry, E. F., "Update on Slurry Transportation From Face to Cleaning Plant," Mining Congress Journal, pp. 14-18, December 1977.

16. Miscoe, A. J., "Hydrotransport In The United States," U.S./D.0.E. Pittsburgh Mining Technology Center Progress Report, August 6, 1979. 